\title{
Analysis of the bond behaviour between prestressed strands and concrete in fire
}

Jamal Khalaf, Zhaohui Huang*

Department of Mechanical, Aerospace and Civil Engineering, College of Engineering, Design and Physical Sciences, Brunel University, Uxbridge, Middlesex, UB8 3PH, UK.

E-mails: jamal.khalaf@,brunel.ac.uk; zhaohui.huang@brunel.ac.uk

\begin{abstract}
In this paper a robust model has been developed to predict the average bond stress-slip relationship between the strands and concrete of prestressed concrete structural members. Two bond-slip curves have been proposed to represent the bond-slip characteristics for the three-wire and seven-wire strands. This model considers the variation of concrete properties, strands' geometries and the type of strand surface, smooth or indented. The degradation of materials and bond characteristic at elevated temperatures are also included in the model. The proposed model has been validated against previous experimental results at both ambient and elevated temperatures.
\end{abstract}

Keywords: Bond-slip, prestressed concrete, strands, fire conditions.

\section{RESEARCH HIGHLIGHTS:}

- Develop a robust model for modelling the bond-slip between concrete and strands for prestressed concrete structures in fire.

- Incorporate the bond-slip model into the 3D finite element analysis of prestressed concrete structures in fire.

- The model has been validated against previous test results and good agreements are achieved.

\footnotetext{
* Corresponding author, E-mail address: zhaohui.huang@brunel.ac.uk (Z. Huang)
} 


\section{NOTATION}

$V_{c} \quad$ Shear force resistance of the concrete in front of strand ridges

$v_{c} \quad$ shear strength of the shear keys in the concrete mass

$A_{s h} \quad$ shear area of the cracked surface

$d_{w} \quad$ diameter of the outer wires

$l_{w} \quad$ length of the wires

$d_{s} \quad$ nominal strand diameter

$F \quad$ force along the length of the wires

$C \quad$ cohesion between the concrete and steel

$\mu \quad$ coefficient of friction

$\theta \quad$ pitch angle of the outer wires

$\tau \quad$ peak shear strength $\left(v_{c}=\tau\right)$

$f_{c}^{\prime} \quad$ concrete compressive strength

$f_{t} \quad$ concrete tensile strength

$\sigma_{n} \quad$ normal stress perpendicular to the strand axes

$P_{1} \quad$ initial tension force on the strand usually equal to $0.75 f_{u}(0.75$ ultimate stress $)$

$P_{2} \quad$ force after the stress released from the strand

$A_{s} \quad$ nominal area of the strand

$E_{S} \quad$ modulus of elasticity of the strand

$v \quad$ Poisson ratio of the steel equal to 0.3

$\varepsilon_{s 1} \quad$ first strain of the strand at $P_{1}$

$\varepsilon_{s 2} \quad$ second strain of the strand at $P_{2}$

$\varepsilon_{c} \quad$ strain of the concrete due to the lateral pressure of strand.

$T_{b} \quad$ maximum bond force in the direction of strand

$\tau \quad$ average bond stress

$\tau_{\max } \quad$ maximum bond stress

$S \quad$ slip between strand and concrete.

$A_{b} \quad$ contact area between the strand and concrete

$\tau_{T} \quad$ bond stress at elevated temperatures

$\tau_{\max , T}$ maximum bond stress at elevated temperatures 


\section{Introduction}

Prestressed concrete (PC) construction has obtained wide popularity in current building construction. PC members can be constructed by utilizing unbonded or bonded strands. For bonded PC members, the bond is essential for the success of prestressing system. The bond in PC members may be categorized as transfer bond and flexural bond. During PC manufacture, strands are initially prestressed by using jacks at the ends abutments. The concrete is cast and cured then the strands are cut. Initial tensioning of the strands causes a reduction of the strands diameter due to Poisson's effect. After concrete reaches sufficient strength, the strands are released from the abutments, and the stress in the strands at the free ends of the members returns to zero. With this reduction of the strand stresses, the diameter of the strand expands along the transfer length and wedging action caused by lateral expansion (called Hoyer effect) results in improved bond performance over the transfer bond length [1]. From the literatures, to determine the bond for the flexural bond length, pull-out tests had been conducted by cast the concrete surround the strand then; the strand is pulled from the concrete with measuring the pull-out force versus the slip. However, the bond for the transfer bond length can be obtained by applying initial prestress on the strand, and then casting the concrete until the time of test, then releasing the stress from the strand gradually with recording of stress released versus the slip [1,2].

For the bonded PC structural members, the force is transferred from strands to concrete through end anchors, together with the bond between strand and concrete. Therefore bonded PC beams are more robust structural members at ambient temperature. However, previous research indicated that compared to normal reinforcing steel, prestressed steel wires are more sensitive to elevated temperatures due to the stress level in prestressing wires is very high [3]. Structural fire safety is one of the most important considerations in building applications. The conventional approach of evaluating fire resistance through fire tests is expensive, time consuming and limited to study different parameters. An alternative to fire testing is the use of numerical modelling for evaluating fire resistance of PC structural members. Numerical methodology allows incorporation of various parameters in an efficient and cost-effective way [4].

Previous research indicated that concrete structures begin losing strength rabidly when temperature reaches higher than $300^{\circ} \mathrm{C}$. The reduction of the concrete strength at elevated temperatures is commonly attributed to the degradation of the calcium silicate hydrate $(\mathrm{C}-\mathrm{S}-\mathrm{H})$ as it begins to lose structural water along with dehydration of other hydrates like calcium hydroxide and ettringite. This dehydration leads to initiate internal thermal stress gradients especially with high density and low porosity of cement past. When temperature increases the water vapour inside the concrete is unable to escape causing pressure that builds up in the pores of concrete. This results in concrete cracking 
and potential damage to the concrete elements, also initiation of thermal incompatibility between aggregates and cement paste which leads to decompose of concrete [5]. On the other hand, exposer of concrete structures to high temperatures leads to significant losses in yield strength of the steel bars. This reduction can reach to half at temperature $550^{\circ} \mathrm{C}$. For the prestress steel, the loss of strength occurs at lower temperatures compared to normal steel rebar. A considerable reduction can occur in prestress steel strength at temperatures $300^{\circ} \mathrm{C}-400^{\circ} \mathrm{C}[6]$. The steel bar as a polycrystalline material has an ordered microstructure consisting of iso-oriented crystalline regions or grains. Some defects and imperfections at the atomic scale called as "dislocations" can be found in the crystalline structure. The creation, multiplication and interaction among the dislocations together with grain size explain why high dislocation densities and small-size grains improve yield strength of a material. At high temperatures the unstable microstructure undergoes a rearrangement of the dislocations leading to a final smaller dislocation density. The smaller dislocation density together with the formation of new grains which are larger than the original grains explains the observed sensitivity of the mechanical properties of the rebar to high temperature [7].

At present, a number of investigations has been conducted to study the bond behaviour between prestressed strands and concrete at ambient temperature [1, 8-11]. However, there are very limited researches conducted for investigating the bond-slip characteristic between prestressed strands and concrete at elevated temperatures. Hence, the main objectives of this paper are:

- To develop a robust model for modelling the bond-slip between concrete and strands for prestressed concrete structures in fire. This model can be used to predict the bond stress-slip for three-wire and seven-wire strands with smooth or indented surface at elevated temperatures.

- Incorporate the bond-slip model into the 3D finite element analysis [12] for prestressed concrete structures under fire conditions.

- To validate the model against previous test results.

\section{Analytical model}

For pretentioned concrete members, there are two distinct regions with different bond characteristics: the transfer bond length region and the flexural bond length region. Figs. 1(a) and 1(b) show the variation of stresses in the pretensioned strand along an unloaded beam after the prestress is released from the strand. Fig. 1(c) shows the variation of stresses in the strand for the same beam which is subjected to external load [1]. The transfer bond length $l_{t}$, as shown in Fig. 1(b) is the distance from the end of the concrete where the strand stress is zero to the point where the 
strand stress reaches to the maximum level for an unloaded beam. The transfer bond length $l_{t}$ can be taken as $\left(50 d_{s}\right)$ [2]. The flexural bond length $l_{f}$ is the length start from the end of the transfer bond length to the point in which the ultimate stress can be developed after loading (see Fig. 1(c)).

When concrete is casted around a strand in prestressed concrete structures, the concrete forms an envelope or sleeve surrounding the strand. The hardened concrete mimics the shape of strands. When the strands are pulled through the concrete, movement is resisted by the concrete keys acting on the outside wires of the strands [13], as shown in Fig. 2. This resistance is called mechanical interlocking.

The mechanisms that contribute to the bond between prestressed strands and surrounding concrete are chemical adhesion, friction and mechanical interlocking between strands' outer wires and concrete. The mechanical interlocking is the largest contributor to the bond, especially in cracked regions. When the cracks are formed in the concrete surrounding a strand, the strand's slip is occurred for some small finite distance on either side of the crack to preserve compatibility of the strand. When the bond's slip occurs, the mechanical interlocking is activated by the reaction of the interlocking of outside wires of the strand with the concrete envelope. The bond's slip is caused mainly by crushing of the concrete in front of the strand's ridges. The high pressure on the concrete in front of the ridges causes tensile stresses in the concrete surrounding the strand, which in turn create internal inclined cracks. These inclined cracks initiate at relatively low bond stresses at the point of contact between the strand and concrete. With increasing induced slip, the concrete in the front of the ridges will be crashed. Increasing the stress in the strand, furthermore slip occurs because of more local crushing takes place; then, shear cracks in the concrete keys between the strand ridges are initiated. At maximum bond resistance, these concrete keys are sheared off [14].

In the proposed model, the shear force resistance (shear force capacity) of the concrete in front of strand ridges $V_{c}$ (as shown in Fig. 2) can be calculated as:

$$
V_{c}=v_{c} A_{s h} n
$$

Where, $v_{c}$ is the shear strength of the shear keys in the concrete mass (concrete shear capacity); $n$ is the number of the outer wires and $A_{s h}$ is the shear area of the cracked surface, which is the area of the concrete keys between two ridges of the strand and equal to the diameter of the outer wires $d_{w}$ by the length of the wires $l_{w}$ (see Fig. 2) as:

$$
A_{s h}=d_{w} l_{w}
$$

Then, the force $F$ along the length of the wires can be found as: 


$$
\begin{aligned}
& F=F_{1}+F_{2} \\
& F_{1}=\mu V_{c}
\end{aligned}
$$

The second part of bond force is achieved by cohesion and friction between the strand and concrete as:

$$
F_{2}=\left(0.6 \pi d_{w}\right) l_{w}\left(C+\mu \sigma_{n}\right) n
$$

Where, $C$ is the cohesion between the concrete and steel and $\mu$ is the coefficient of friction between steel and concrete. Based on References $[2,15,16]$, the values of $C$ and $\mu$ can be assumed as stated in Table 1. In this proposed model, the value of $\mu$ is assumed to be the same at ambient and elevated temperatures, while the cohesion $C$ is assumed to be zero when temperature $>400{ }^{\circ} \mathrm{C}$. The maximum bond force in the direction of the strand $T_{b}$ is calculated as:

$$
T_{b}=F / \cos (\theta)
$$

where, $\theta$ is the pitch angle of the outer wires, which can be taken as $\left(\theta=9^{\circ}\right)[13]$.

The shear strength of the concrete mass $v_{c}$ in Eq. (1) should not be assumed greater than $0.2 f_{c}^{\prime}$ [13]. The value of the shear strength of the concrete keys $v_{c}$ can be calculated by using Parabolic Mohr Envelope [17]. Fig. 3 shows a parabolic fit to Mohr circles for uniaxial compression and tension test results [17]. From Fig. 3 the shear strength envelope is defined as follows:

$$
\tau^{2}=\left[f_{c}^{\prime}-2 f_{t}\left(-1+\sqrt{1+\frac{f_{c}^{\prime}}{f_{t}}}\right)\right]\left(\sigma_{n}+f_{t}\right)
$$

where, $\sigma_{n}$ is the normal stress perpendicular to the strand axes.

For the pull-out bond which represents the bond for flexural bond length, $\sigma_{n}=0$ then

$$
\tau=c=v_{c}=f_{t}\left(\frac{f_{c}^{\prime}}{f_{t}}+2-2 \sqrt{1+\frac{f_{c}^{\prime}}{f_{t}}}\right)^{1 / 2}
$$

For the push-in bond which represents the bond for transfer bond length $\sigma_{n} \neq 0$, this means that there is a pressure normal to the axes of the strand inside the concrete. $\sigma_{n}$ can be calculated based on the stress-strain relation defined in Eurocode 2 [18] for non-linear structural analysis as $\sigma_{n}=\sigma_{c}$; that is: 


$$
\begin{aligned}
& \sigma_{n}=\sigma_{c}=f_{c m} \frac{k \eta-\eta^{2}}{1+(k-2) \eta} \\
& \eta=\varepsilon_{c} / \varepsilon_{c 1} \\
& \varepsilon_{c 1}=0.7 f_{c m}^{0.31} \leq 2.8 \\
& k=1.05 E_{c m}\left|\varepsilon_{c 1}\right| / f_{c m}
\end{aligned}
$$

where, $\varepsilon_{c 1}$ is the strain at peak stress (Table 3.1 in Eurocode 2 [18]) and $\varepsilon_{c}$ is the concrete strain taken from Eq. (15).

Normal pressure $\sigma_{n}$ in prestressed concrete can be generated from the effect of Poisson ratio (Hoyer effect). This is due to the released prestressed strand after concrete casting; the nominal diameter of the strand will increase due to Poisson ratio. This radial expansion generates normal stresses in the concrete surround the strand. These stresses give extra confinement to the strand and result in increasing of the bond stress between the strand and concrete. This expansion in strand diameter can be calculated as:

$$
\begin{aligned}
& \frac{P_{1}}{A_{s} E_{s}}=\varepsilon_{s 1} \\
& \frac{P_{2}}{A_{s} E_{s}}=\varepsilon_{s 2} \\
& \varepsilon_{c}=\frac{P_{1}-P_{2}}{A_{s} E_{s}} v=\left|\varepsilon_{s 1}-\varepsilon_{s 2}\right| v
\end{aligned}
$$

Where, $P_{1}$ is the initial tension force on the strand which typically taken as $70-75 \%$ of the ultimate stress multiplied by the cross section area of the strand [1,9]. $P_{2}$ is the force after the stress released from the strand in which the effective force $\Delta P$ on the strand is $\Delta P=P_{1}-P_{2}$. In PC members when the strand is cut, $P_{2}$ equals to zero then the effective force $\Delta P$ equals to $P_{1}$.

As shown in Fig. 4, the average bond stress-slip relationship between the concrete and deformed bar defined by CEB-FIP Model code 2010 [19] has been adopted in this study. In Fig. 4, $\tau$ is the average bond stress; $\tau_{\max }$ is the maximum bond stress; $S$ is the slip between strand and concrete.

For three-wire smooth and indented, and seven-wire indented strands, the curve can be defined as follow:

$$
\tau=\left(S / S_{1}\right)^{\alpha} \quad \text { for } 0 \leq S \leq S_{1}
$$




$$
\begin{aligned}
& \tau=\tau_{\text {max }} \quad \text { for } S_{1} \leq S \leq S_{2} \\
& \tau=\tau_{\text {max }}-\left(\tau_{\text {max }}-\tau_{3}\right)\left(S-S_{2}\right) /\left(S_{3}-S_{2}\right) \quad \text { for } S_{2} \leq S \leq S_{3} \\
& \tau=\tau_{f} \quad \text { for } \quad S>S_{3}
\end{aligned}
$$

For seven-wire smooth strands the curve is defined as:

$$
\begin{array}{ll}
\tau=\left(S / S_{1}\right)^{\alpha} \quad \text { for } 0 \leq S \leq S_{1} & \\
\tau=\tau_{\max }-\left(\tau_{\max }-\tau_{2}\right)\left(S-S_{1}\right) /\left(S_{2}-S_{1}\right) & \text { for } S_{1} \leq S \leq S_{2} \\
\tau=\tau_{2}+\left(\tau_{\max }-\tau_{2}\right)\left(S-S_{2}\right) /\left(S_{3}-S_{2}\right) & \text { for } S_{2} \leq S \leq S_{3} \\
\tau=\tau_{\max }-\left(\tau_{\max }-\tau_{4}\right)\left(S-S_{3}\right) /\left(S_{4}-S_{3}\right) & \text { for } S_{3} \leq S \leq S_{4} \\
\tau=\tau_{f} \quad \text { for } \quad S>S_{4} &
\end{array}
$$

In the current model, $\tau_{\max }$ can be calculated as:

$$
\tau_{\max }=\frac{T_{b}}{A_{b}}
$$

where, $T_{b}$ is the maximum bond force which is calculated from Eq. (6) and $A_{b}$ is the contact area between the strand and concrete as:

$$
A_{b}=\pi d_{s} L_{b}
$$

where, $d_{s}$ is the nominal diameter of the strand and $L_{b}$ is the embedded length of the strand.

The values of parameters $S_{1}, S_{2}, S_{3}$ and $S_{4}$ are assumed based on statistical analysis of the experimental results from the previous researches $[1,9-11,16]$ as given in Tables 2 and 3 for threewire and seven-wire strands, respectively.

\section{Effect of elevated temperatures}

Exposure of concrete structures to high temperatures leads to significant losses in mechanical and physical properties of concrete and strand as well as the bond characteristics between them [20]. In this research the effect of high temperatures on the bond characteristics is considered by taking into account the degradation of concrete properties at elevated temperatures. The concrete properties at ambient temperature specified in Eurocode 2 EN 1992-1-1 [18] are used. The compressive strength and elastic modulus of concrete at elevated temperatures are calculated based on Eurocode 2 EN 1992-1-2 [21]. However, the degradation of the concrete tensile strength at elevated temperatures 
$f_{c t, T}$ specified in Eurocode 2 EN 1992-1-2 is not used in this research. This is mainly due to $f_{c t, T}=0$ when the concrete temperature is higher than $600{ }^{\circ} \mathrm{C}$ [21]. Hence, the degradation of the tensile strength for concrete at elevated temperatures proposed by Aslani and Bastami [22] is adopted in this study. That is:

$$
f_{c t, T}=f_{c t}\left[\begin{array}{lc}
1.02-0.00098 \times T & 20<T \leq 300^{\circ} \mathrm{C} \\
0.965-0.0001 \times T-9 \times 10^{-7} T^{2}-3 \times 10^{-9} T^{3}+3.2 \times 10^{-12} T^{4} & 300<T \leq 900^{0} \mathrm{C} \\
0.0 & T>900{ }^{\circ} \mathrm{C}
\end{array}\right]
$$

where, $f_{c t}$ is the concrete tensile strength at ambient temperature and $T$ is the concrete temperature. By considering the degradation of concrete properties at elevated temperatures, the bond stress $\tau$ and maximum bond stress $\tau_{\max }$ are temperature dependent.

Previous researches [8-10] indicated that bond strength between concrete and strand is mainly affected by the concrete characteristics surround the strands. When the compressive and tensile strengths of the concrete increased, the shear resistance of the concrete will increase. This results in increasing bond strength. However, the degradation of concrete strengths under fire condition leads to high reduction in bond strength, as the maximum bond stress $\tau_{\max }$ depends on the concrete shear strength and the interlocking between the strands and concrete. The strength of steel strand is significantly reduced at elevated temperatures, however, the degradation of steel strands at high temperatures has relatively smaller influence on the bond strength between the concrete and strands [8-10].

In the current model the steel strand is modelled using three-node beam element. The material degradation and thermal expansion of the steel strand is considered in the model. However, the influence of the strength reductions of steel strand on the bond strength is ignored in the model. Previous researchers $[2,15,16]$ found that the coefficient of friction between concrete and steel strand is not sensitive to the temperature variations. Hence, in the current model, the coefficient of the friction $(\mu)$ between steel strand and concrete is temperature independent and the coefficient of the cohesion $C$ is assumed to be zero when temperature $>400^{\circ} \mathrm{C}$.

The procedure for calculating the maximum bond stress of prestressed concrete $\tau_{\max }$ can be summarised as follow:

(1) Define the parameters for the concrete and strands (compressive strength and modulus of elasticity of the concrete, yield stress, Young's modulus, diameter, number of wires and surface condition of the strand), as well as, the initial force on the strand.

(2) Based on the strand's conditions to define the values of $C$ and $\mu$ from Table 1 . 
(3) Calculate the material properties of concrete at elevated temperatures.

(4) Calculate the radial strain of the concrete surround the strand $\varepsilon_{c}$ (Eq. (15)) and the radial stress $\sigma_{n}$ from (Eq. (9)) (resulted from the effect of Poisson's ratio).

(5) Calculate the shear strength of the concrete shear keys $v_{c}$ (Eq. (8)).

(6) Calculate the shear area of the cracked surface $A_{s h}$ (Eq. (2)).

(7) Calculate the shear force capacity of the concrete keys $V_{c}$ (Eq. (1)).

(8) Calculate the force along the length of the wires $F=F_{1}+F_{2}$ (Eq. (3), Eq. (4) and Eq. (5)).

(9) Calculate the maximum bond force $T_{b}$ (Eq. (6)) and the contact area $A_{b}$ (Eq. (26)) between the strand and concrete.

(10) Finally the maximum bond stress $\tau_{\max }$ can be calculated from (Eq. (25)).

\section{Integrating the bond stress-slip model into 3D finite element procedure}

The bond-slip model proposed above has been incorporated into 3D finite element procedure within Vulcan software $[12,20]$ in order to model prestressed concrete structures in fire. In recent years, a two-node bond-link element has been developed to simulate the effect of bond-slip between the reinforcing steel and concrete at elevated temperatures, as shown in Fig. $5[12,20]$. The framework of the bond-link element is used to integrate the current bond-slip model into 3D finite element model for simulating the bond characteristic between the strand and concrete in PC members. For the bond element, the bonding force $F_{x, T}$ between the concrete and strand is obtained as:

$$
F_{x, T}=A \tau
$$

where, $A$ is the contact area between the concrete and strand $(A=U L)$, where $U$ is the perimeter of the strand and $L$ is the length of the strand which contributes to the node connected by the bond element.

In the local co-ordinate, referenced to the strand element, the nodal force increment vector, $\mathbf{\Delta} \mathbf{F}$ of the element can be related to its nodal displacement increment vector $\Delta \mathbf{u}$ as: 


$$
\left\{\begin{array}{l}
\Delta F_{x, 1} \\
\Delta F_{y, 1} \\
\Delta F_{z, 1} \\
\Delta M_{x, 1} \\
\Delta M_{y, 1} \\
\Delta M_{z, 1} \\
\Delta F_{x, 2} \\
\Delta F_{y, 2} \\
\Delta F_{z, 2} \\
\Delta M_{x, 2} \\
\Delta M_{y, 2} \\
\Delta M_{z, 2}
\end{array}\right\}=\left[\begin{array}{cccccccccccc}
k_{1} & 0 & 0 & 0 & 0 & 0 & -k_{1} & 0 & 0 & 0 & 0 & 0 \\
0 & k_{2} & 0 & 0 & 0 & 0 & 0 & -k_{2} & 0 & 0 & 0 & 0 \\
0 & 0 & k_{3} & 0 & 0 & 0 & 0 & 0 & -k_{3} & 0 & 0 & 0 \\
0 & 0 & 0 & k_{4} & 0 & 0 & 0 & 0 & 0 & -k_{4} & 0 & 0 \\
0 & 0 & 0 & 0 & k_{5} & 0 & 0 & 0 & 0 & 0 & -k_{5} & 0 \\
0 & 0 & 0 & 0 & 0 & k_{6} & 0 & 0 & 0 & 0 & 0 & -k_{6} \\
-k_{1} & 0 & 0 & 0 & 0 & 0 & k_{1} & 0 & 0 & 0 & 0 & 0 \\
0 & -k_{2} & 0 & 0 & 0 & 0 & 0 & k_{2} & 0 & 0 & 0 & 0 \\
0 & 0 & -k_{3} & 0 & 0 & 0 & 0 & 0 & k_{3} & 0 & 0 & 0 \\
0 & 0 & 0 & -k_{4} & 0 & 0 & 0 & 0 & 0 & k_{4} & 0 & 0 \\
0 & 0 & 0 & 0 & -k_{5} & 0 & 0 & 0 & 0 & 0 & k_{5} & 0 \\
0 & 0 & 0 & 0 & 0 & -k_{6} & 0 & 0 & 0 & 0 & 0 & k_{6}
\end{array}\right]\left\{\begin{array}{l}
\Delta u_{1} \\
\Delta v_{1} \\
\Delta w_{1} \\
\Delta \theta_{x, 1} \\
\Delta \theta_{y, 1} \\
\Delta \theta_{z, 1} \\
\Delta u_{2} \\
\Delta v_{2} \\
\Delta w_{2} \\
\Delta \theta_{x, 2} \\
\Delta \theta_{y, 2} \\
\Delta \theta_{z, 2}
\end{array}\right\}
$$

For the strand, apart from the relative slip along the longitudinal axis direction ( $x$-direction) between concrete and strand, the concrete prevents relative movement of the strand in other directions. It is therefore reasonable to assume that common nodes of the concrete and strand elements have identical rotations and movements in $y$ and $z$ directions. Hence, in this model $k_{2}, k_{3}, k_{4}, k_{5}, k_{6}$ in Eq. (29) are assumed to have infinite magnitude $\left(=10^{15}\right)$.

Coefficient $k_{1}$ is the tangent stiffness coefficients of the bond-link element related to the axis of the strand element which can be determined from the load-slip relationship as:

$$
k_{1}=\frac{d F_{x, T}}{d s}=A \frac{d \tau}{d s}
$$

Coefficient $k_{1}$ for three-wire smooth and indented strands and seven-wire indented strands can be obtained by using Eqs. (16) to (19) as follow:

$$
\begin{array}{ll}
k_{1}=\frac{A \tau_{\text {max }}}{s_{1}}\left(\frac{s}{s_{1}}\right)^{\alpha-1} & \text { for } 0 \leq s \leq s_{1} \\
k_{1}=0.0 & \text { for } s_{1}<s \leq s_{2} \\
k_{1}=-\left(\frac{\tau_{\max }-\tau_{3}}{s_{3}-s_{2}}\right) & \text { for } s_{2}<s \leq s_{3} \\
k_{1}=0.0 & \text { for } s_{3}<s
\end{array}
$$

For seven-wire smooth strand, $k_{1}$ can be calculated using Eqs. (20) to (24) as follow:

$$
k_{1}=\frac{A \tau_{\max }}{s_{1}}\left(\frac{s}{s_{1}}\right)^{\alpha-1} \quad \text { for } 0 \leq s \leq s_{1}
$$




$$
\begin{array}{lr}
k_{1}=-\left(\frac{\tau_{\text {max }}-\tau_{2}}{s_{2}-s_{1}}\right) & \text { for } s_{1}<s \leq s_{2} \\
k_{1}=\left(\frac{\tau_{\max }-\tau_{2}}{s_{3}-s_{2}}\right) & \text { for } s_{2}<s \leq s_{3} \\
k_{1}=-\left(\frac{\tau_{\max }-\tau_{4}}{s_{4}-s_{3}}\right) & \text { for } s_{3}<s \leq s_{4} \\
k_{1}=0.0 & \text { for } s_{4}<s
\end{array}
$$

Using incremental analysis, the increment of bond force $\Delta F_{x}$ can be related to the increment of slip, $\Delta s$ by the tangent stiffness relationship as:

$$
\begin{aligned}
& \Delta F_{x, T}=k_{1} \Delta s \\
& \Delta s=\Delta u_{1}-\Delta u_{2}
\end{aligned}
$$

where, $\Delta u_{1}$ and $\Delta u_{2}$ are the increments of displacement in the direction of $\Delta F_{x, T}$ at the nodes 1 and 2 of the bond-link element, respectively.

The bond-link element permits the modelling of full, partial and zero interaction at the interface between concrete and strands. In this non-linear incremental analysis procedure, the total slip of a bond element at any load level is calculated from the incremental slips of that bond element. The bond force corresponding to total slip is calculated from the incremental forces determined by Eq. (40), and the tangent stiffness of the bond element is calculated using Eqs. (30) to (39).

As shown in Fig. 5, in the current model a PC beam is represented as an assembly of plain concrete beam, strand and bond-link elements. Both plain concrete and strand elements are modelled using a 3-node beam element. Three bond-link elements are used to connect a plain concrete element with a strand element. For plain concrete and strand elements the thermal expansions and material degradations of concrete and steel at elevated temperatures are considered. Hence their effect, related to the direction of longitudinal axis of strand, on the bond-link element developed in this paper is taken into account. However, the thermal expansions of both concrete and strand in the radius direction of the strand have not been considered in the current model for simplicity. This is because that the strain compatibility at the interface between the strand and surrounding concrete is not always maintained when the pull-out load is applied [20], especially when the pull-out load reaches the capacity of a bond. From the authors' knowledge, a PC beam member needs to be modelled at least two or more plain concrete and strand elements depending on the length of the 
beam modelled. It is suggested that the size of the plain concrete and steel strand elements are less than $1 \mathrm{~m}$.

The plain concrete beam is modelled using the 3-node beam elements. The cross-section of the beam element is sub-divided into segments to consider the temperature variation within the crosssection [12]. Hence, in principal the temperature variation within the concrete rings around the strand can be considered in the current model. However, in the following validation section it is assumed that the temperatures of the concrete rings around the strands are uniform and equal to the temperature of strand for simplicity. This is a reasonable assumption for all pull-out tests [20].

At ambient temperature, PC members incur initial camber due to prestressing. This prestressing effect can be modelled in the current model by applying an initial tension strain on the strand's elements which can be calculated as the prestress (usually about $70 \%$ of the strand yield stress) divided by the strand young modulus.

\section{Validations}

There are two sections for presenting the validations of the proposed model. The first section is to validate the bond stress-slip curve at ambient and elevated temperatures and the second section is to consider the structural response at ambient and under fire conditions using previous structural experimental results.

\subsection{Validations of bond stress-slip curve at ambient and elevated temperatures}

In this section, different cases of bond-slip curves have been used for the validations. Three parts are conducted in order to validate the accuracy and capability of the proposed model. The first part is to consider the transfer and flexural bonds by using push-in and pull-out tests, respectively. The second part is to examine seven-wire strands with both smooth and indented surface conditions. The third part is to validate three wire-strands with smooth and indented surfaces.

\subsubsection{Transfer and flexural bonds at ambient temperature}

Abrishami and Mitchell [1] conducted a series of tests to study the bond stress-slip between sevenwire smooth strands and concrete. The tested material properties are as follows: the cylinder concrete compressive strength was $25 \mathrm{MPa}$ at the time of testing; the prestressing steels were sevenwire strands with the nominal diameters of $9.5,13$ and $16 \mathrm{~mm}$. The strands with 9.5 and $13 \mathrm{~mm}$ diameter had an ultimate tensile strength of $1860 \mathrm{MPa}$ and the $16 \mathrm{~mm}$ diameter strand had an ultimate tensile strength of $1760 \mathrm{MPa}$. Table 4 gives the details of the specimens tested for transfer bond as well as a comparison of the measured and predicted bond strengths. Table 5 shows the 
details of the specimens tested for transfer bond as well as a comparison of the measured and predicted bond strengths. It can be seen from Tables 4 and 5 that the predictions by proposed model agreed well with the test results.

\subsubsection{Seven-wire smooth and indented strands at ambient temperature}

Vázquez-Herrero et al. [9] conducted a test on the bond stress-slip between strand and concrete. In this test, seven-wire smooth strand and a cylinder specimen of normal concrete with dimensions of $150 \times 300 \mathrm{~mm}$ were used. The tested material properties of concrete are: compressive strength was $49 \mathrm{MPa}$, tensile strength was 2.9 MPa. The properties of seven-wire smooth strand are: nominal diameter was $15.2 \mathrm{~mm}$, average elastic modulus was $197.4 \mathrm{GPa}$, breaking strength was $260 \mathrm{kN}$, and the cross section area was $142 \mathrm{~mm}^{2}$. Fig. 6 shows the predicted bond stress-slip curve together with the test results. It is evident that good agreement was achieved between the predictions and test results.

A flexural bond test of seven-wire indented strand conducted by Lundgren [10] was used to investigate the bond behaviour of this type of strand. The diameter of the strand was $12.9 \mathrm{~mm}$. The tested concrete compressive strength was $63 \mathrm{MPa}$ and Young's modulus was $36 \mathrm{GPa}$. Fig. 7 presents the comparison of predicted pull-out load versus bond slip curve against the test results. It can be seen that good agreement between the predictions and test results was achieved.

\subsubsection{Three-wire indented and smooth strands at ambient temperature}

Gustavson [11] studied the bond characteristics of three-wire smooth and indented strands. In this study two types of bond test were conducted which were flexural and transfer bond tests. For the transfer bond test, the indented strand used was EU 138/6 with nominal diameter of $6.5 \mathrm{~mm}$. The strand was prestressed with a force of $28 \mathrm{kN}$, corresponding to a prestress of $1320 \mathrm{MPa}$. The tested concrete compressive strength was $25 \mathrm{MPa}$. For the flexural bond test, the smooth strand with 6.5 $\mathrm{mm}$ diameter was used. The tested concrete compressive strength was $55 \mathrm{MPa}$. Fig. 8 shows the comparison of predicted and tested load-slip curves for the transfer bond test. Fig. 9 illustrates the comparison of predicted and tested load-slip curves for the flexural bond tests. It is clear that reasonable agreements were obtained for both tests.

\subsubsection{Bond stress-slip curve at elevated temperatures}

Moore [23] studied the bond-slip characteristics of strands at elevated temperatures. Seven-wire low relaxation strands with grade 270 were used in this investigation. The diameter of strand was $12.7 \mathrm{~mm}$. Two types of concrete with different compressive strengths of $77.4 \mathrm{MPa}$ and $98.8 \mathrm{MPa}$ were used in the test. Pull-out specimens were $152.4 \times 152.4 \times 101.6 \mathrm{~mm}$ with embedded length of 
$101.6 \mathrm{~mm}$. The specimens were heated with a heating rate of $4.4{ }^{\circ} \mathrm{C} / \mathrm{min}$. Six temperatures of 20 , 260, 427, 538, 649 and $704{ }^{\circ} \mathrm{C}$ were adopted. The specimens were heated until the designated temperatures were reached. Fig. 10 shows the comparisons of the bond strength degradation (referenced to ambient temperature) at elevated temperatures between the predicted and tested results. Again, reasonable agreements were achieved.

\subsection{Validations of structural behaviour of prestressed concrete members}

In this section, two tests of simply supported PC beams and two tests of simply supported PC slabs at both ambient and elevated temperatures were used to validate the developed model. In all validation cases both material and geometric non-linearity were considered. The predicted results were compared with the experimental results to demonstrate the robustness and accuracy of the developed model.

\subsubsection{Modelling of simply supported PC beams at ambient temperature}

Two different experimental studies on the simply supported PC beams have been modelled to validate the capability of the proposed model.

The first experimental study on a simply supported T-beam Z-1 was carried out by Cowen and VanHorn [24]. The details of the tested beam are shown in Fig. 11. The strands used in this study were seven-wire $270 \mathrm{~K}$ strands with diameter of $12.7 \mathrm{~mm}$. These strands were located in the three layers within the cross-section, as shown in Fig. 11. The strands were initially tensioned to a stress level of $70 \%$ of the specified ultimate stress (which was $1303 \mathrm{MPa}$ ) and the average effective prestress force at the time of the test was $128.5 \mathrm{kN}$. The concrete compressive strength at the time of the test was $42.4 \mathrm{MPa}$ and the Young's modulus was $28.9 \mathrm{GPa}$. By applying symmetry only half of the T-beam was modeled. In the modelling, 5 three-node plain concrete elements, 25 three-node strands elements and 55 bond-link elements were employed. By taking the value of $50 d_{s}$, the transfer length was $635 \mathrm{~mm}$ from the end of the beam, therefore the first 5 bond-link elements were modelled as transfer bond and the rest of 50 bond-link elements were represented as flexural bond. The initial prestressed force was $128.5 \mathrm{kN}$ which can be applied as initial strain of 0.0055 on the strand's elements. The comparison between the predicted load versus mid-span deflection curves against the tested results is shown in Fig. 12. It is clear that the proposed model achieved a good agreement with the test data.

The second test on a simply supported T-girder (T-6-1.5h-A) of $8534.4 \mathrm{~mm}$ long was done by Tadros and Morcous [25]. In this test, Grade 270 low relaxation prestressing seven-wire strands with diameter of $17.78 \mathrm{~mm}$ was used. As shown in Fig. 13, six strands were located in two rows 
with $50.8 \mathrm{~mm}$ concrete cover and strand spacing. Concrete compressive strength at the time of the test was $62.0 \mathrm{MPa}$. Only half of the girder was modeled due to symmetry. 5 three-node plain concrete elements, 30 three-node strands elements and 66 bond-link elements were employed. The transfer length was $889 \mathrm{~mm}$ from the end of the beam, thus 6 bond-link elements were modelled as transfer bond and the rest of 60 bond-link elements were represented flexural bond. The initial prestress strain of 0.003 was applied on the strand's elements. The comparison between the predicted load versus mid-span deflection curves against the tested results is shown in Fig. 14. Again, the predictions by the proposed model agreed well with the test results.

\subsubsection{Modelling fire tests of simply supported PC slabs}

Two slabs have been modelled for the validation of the current model at elevated temperatures. The first slab was simply supported PC Slab TB3 tested by Bailey and Ellobody [26]. The slab was $4.0 \mathrm{~m}$ length by $1.6 \mathrm{~mm}$ width with thickness of $0.16 \mathrm{~m}$. Fig. 15 illustrates the details of TB3 slab. The tested slab was subjected to the standard time-temperature curve specified in BS EN1991-1-2 [27] by using gas furnace. The slab was heated over a middle length of $3.2 \mathrm{~m}$ out of its $4.0 \mathrm{~m}$ as shown in Fig. 15. The tested concrete compressive strength at the time of test was $36.6 \mathrm{MPa}$, the strand was $15.7 \mathrm{~mm}$ seven-wire smooth strand of grad 270 with yield stress of $1675 \mathrm{MPa}$. Those tested material properties were used as an input data for the modelling. Due to the symmetry of the slab, only half of the slab was modelled.

Two steps were followed for modelling the tested slab. For the first step, the thermal analysis was performed. The cross section of the slab was divided into segments for the analysis. During the test, there was no evidence of concrete spalling on the heated surface; therefore, the spalling has not been considered in the thermal analysis. The predicted and tested temperature histories throughout the cross section of the slab at mid-span are shown in Fig. 16. In the figure T indicates the strand; HS, MS and CS represent the hot bottom surface, mid-height and cold top surface of the slab. The predicted temperature histories of the strands and concretes from the thermal analysis were used as the temperature input data for the structural analysis.

For the structural analysis, Slab TB3 was modelled using 5 three-node plain concrete elements, 15 three-node strand elements and 33 bond-link elements. The transfer bond length of $50 d_{s}$ was $785 \mathrm{~mm}$ from the end of the slab, hence 3 bond-link elements were modelled as transfer bond and the rest of 30 bond-link elements were represented as flexural bond. In the structural modelling the reference axis was assumed to coincide with the central axis of plain concrete elements. The real positions of the strand elements within the cross-section of the slab and along the slab were considered in the modelling. The average applied design prestress force in the three strands after 
pre-tension was $169 \mathrm{kN}$. This force can be modelled as an initial strain of 0.0045 to the strands to simulate the prestress on the strands. Same segmentation of the cross section of the slab used in the thermal analysis was adopted for the structural analysis. The total vertical load of $41.6 \mathrm{kN}$ (which represents $60 \%$ of the load capacity) was applied to the slab. This static load was kept constant during fire test.

Fig. 17 shows the comparison of the predicted and measured mid-span deflections of Slab TB3. The predicted and tested longitudinal expansions of Slab TB3 are shown in Fig. 18. It is evident that the predictions by the current model agreed reasonably well with the test results.

The second fire test on a simple supported PC Slab PSS-1 was conducted by Zheng and Hou [28]. As shown in Fig. 19, the slab was $5.3 \mathrm{~m}$ x $0.6 \mathrm{~m} \times 0.09 \mathrm{~m}$. The tested slab was subjected to the standard IOS 834 fire curve. However, as shown in Fig. 20, the average measured furnace temperatures were lower than ISO 834 fire curve. This measured time-temperature curve was used for the thermal analysis to predict the temperature distribution histories within the cross-section of the slab.

During the test, there were very little concretes spalled on the heated surface. Therefore, the spalling has not been considered in the thermal analysis for this test. In the thermal analysis, the crosssection of the tested slab was divided into 280 segments. Fig. 21 shows the predicted and tested temperature histories at the position D1 (exposure surface to the fire) and position D2 (27 mm away from the exposure surface to the fire) within the cross-section of the slab. The predicted temperature histories within the cross-section of the slab were used as the temperature input data for structural analysis.

The tested concrete compressive strength at the time of test was $32.0 \mathrm{MPa}$, the strand was $5.0 \mathrm{~mm}$ seven-wire smooth strand with yield strength of $1498 \mathrm{MPa}$. The additional reinforcing steel bars were $6.5 \mathrm{~mm}$ with yield strength of $328 \mathrm{MPa}$ and $8.0 \mathrm{~mm}$ with yield strength of $320 \mathrm{MPa}$. Those tested material were used as the input data for modelling the slab.

For structural analysis, Slab PSS-1 was modelled using 8 three-node plain concrete elements, 24 three-node strands elements and 51 bond-link elements. The transfer bond length was $250 \mathrm{~mm}$ at both ends of the slab; hence 3 bond-link elements were modelled as transfer bond at each end and the rest bond-link elements were represented as flexural bond within the middle of the slab. Again the reference axis was assumed to coincide with the central axis of plain concrete elements. The real positions of the strand elements within the cross-section of the slab and along the slab were considered in the modelling. The prestress force in the strands for pre-tension was $70.7 \mathrm{kN}$. This force was applied as initial strain of 0.0046 to the strands to simulate the prestress on the strands in 
the model. The segmentation of the cross sections for the plain concrete elements was the same as the thermal analysis. The applied load was 5 point load of $1.53 \mathrm{kN}$ (including the self-weight of the slab) which represents 0.35 of the load capacity of the slab. This static load was kept constant during the fire test. Fig. 22 shows the comparison of the predicted and measured mid-span deflections of Slab PSS-1. It is clear that the predictions by current model agreed well with the test results.

In this section, two large scale ambient temperature tests on PC structural members and two large scale fire tests on PC slabs conducted by different researchers were modelled to validate the model developed in this paper. It is important to mention that the influence of bond between concrete and steel strand on the structural behaviour of PC structural members at ambient temperature is not significant due to high interaction between the concrete and strands. Hence, it is reasonable to assume the full interaction between concrete and steel strand for modelling PC member at ambient temperature. However, the effect of the bond at elevated temperatures is significant because of the considerable degradation of bond strength at elevated temperatures. As shown in Fig. 10, when the temperature is higher than $450^{\circ} \mathrm{C}$, the bond strength reduces to $60 \%$ of the original strength at ambient temperature. Hence, for fire resistance design of PC structural member it is unconservative to assume fully bounded between concrete and steel strand.

\section{Conclusions}

In this paper a new analytical model has been developed to predict the bond stress-slip between strands and concrete for prestressed concrete members under fire conditions. The model is based on the mechanical interlocking between the prestressed steel strands and surrounding concrete as well as the effect of Poisson ratio (Hoyer effect). The model takes into account the variation of the concrete properties and strands' geometries. The degradation of the bond strength at elevated temperatures is related to the concrete material properties changed with temperature. The developed bond stress-slip model has been incorporated into two-node bond-link element within the Vulcan software for analysing the structural behaviours of prestressed concrete structural members in fire. A series of validations have been conducted using the previous tested data generated by different researchers and reasonable agreements have been achieved between the model's predictions and tested results. The model presented in this paper is able to predict the bond-slip characteristic between the concrete and strands for three-wire and seven-wire strands at elevated temperatures. This model can be used to calculate the bond-slip for the transfer bond and flexural bond. Also, the model is able to take into account different strand's diameters and different strand's surfaces (smooth or indented). 


\section{ACKNOWLEDGMENTS}

The authors gratefully acknowledge the financial support of the Ministry of Higher Education and Scientific Research of Iraqi government for this $\mathrm{PhD}$ project.

\section{REFERENCES}

[1] Abrishami H.H., Mitchell D. Bond Characteristic of Pretensioned Strand. ACI Material Journal 1993;90(3):228-235.

[2] CEB-FIP, fib Bulletin 10. Bond of reinforcement in concrete. State-of-art report prepared by Task Group Bond Models 2000.

[3] Hou X., Kodur V.K.R., Zheng W. Factors governing the fire response of bonded prestressed concrete continuous beams. Material and Structures 2015; 48:2885-2900.

[4] Kodur V.K. R., Shakya A. M., Modeling of the response of precast prestressed concrete hollow-core slabs exposed to fire. PCI Journal 2014: 78-94.

[5] Rivera O.G., Long W.R., Weiss Jr C.A., Moser R.D., Williams B.A., Torres-Cancel K., Gore E.R., Allison P.G. Effect of elevated temperature on alkali-activated geopolymeric binders compared to Portland cement-based binders. Cement and Concrete Research 2016; 90: 43-51.

[6] ASHI Reporter, The Effects of Fire on Structural Systems, American Society of Home Inspectors, 2007.

[7] Kumar V., Sharma U.K., Singh B., Bhargava P. Effect of temperature on mechanical properties of pre-damaged steel reinforcing bars. Construction and Building Materials $2013 ; 46: 19-27$.

[8] Galvez J.C., Benitez J.M., Tork B., Casati M.J., Cendon D.A. Splitting failure of precast prestressed concrete during the release of the prestressing force. Engineering Failure Analysis 2009;16: 2618-2634.

[9] Vázquez-Herrero C., Martínez-Lage I., Aguilar G. Evaluation of strand bond properties along the transfer length of prestressed lightweight concrete members. Engineering Structures 2013; 49:1048-1058.

[10] Lundgren K. Steel-Encased Pull-Through Tests of Seven-Wire Strands. Department of Structural Engineering Concrete Structures, Chalmers University of Technology, Sweden 2002, Report No. 02:13.

[11] Gustavson R. Experimental studies of the bond response of three-wire strands and some influencing parameters. Materials and Structures 2004 ;37: 96-106.

[12] Huang Z. Modelling the bond between concrete and reinforcing steel in fire. Engineering Structures 2010; 32:3660-3669. 
[13] Russel B. W., Burns N. H. Design guidelines for transfer development and deboning of large diameter seven wire strands in pretensioned concrete girders. The University of Texas at Austin 1993; Research Report 1210-5F.

[14] Choi O. C., Choi H. J. Bearing angle model for bond of fractioning bars to concrete. Korea Concrete Institute 2010; ISBN 978-89-5708-181-5.

[15] Brown C. J., Darwin D., McCabe S. L. Finite element fractures analysis of steel-concrete bond. Center for Research, University of Kansas 1993; SM Report No. 36.

[16] Bolmsvik R., Lundgren K. Modelling of bond between three-wire strands and concrete. Magazine of concrete research 2006; 58(3):123-133.

[17] Curtis D. D. Estimated shear strength of shear keys and bonded joints in concrete dams. 31st Annual USSD Conference, San Diego, California 2011; 11-15.

[18] Eurocode 2 EN 1992-1-1: design of concrete structures - Part 1-1: general rules and rules for buildings, British Standards Institution, London 2004.

[19] CEB-FIP, fib Bulletin 55, Model code 2010, First complete draft, Volume 1.

[20] Khalaf J., Huange Z., Fan M. Analysis of bond-slip between concrete and steel bar in fire. Computers and Structures 2016;162:1-15.

[21] EN 1992-1-2. Eurocode 2, design of concrete structures - Part 1-2: general rules structural fire design, British Standards Institution, London 2004.

[22] Aslani F., Bastami M. Constitutive relationships for normal-and high-strength concrete at elevated temperatures. ACI Material Journal 2011;108(4):355-64.

[23] Moore W. L. Performance of fire-damaged prestressed concrete bridges. Masters Theses, Missouri University of Science and Technology 2008.

[24] Cowen H. S., VanHorn A. D. End support on ultimate flexural bond in pre-tensioned beams. Bond in prestressed concrete progress report No. 3, Fritz engineering laboratory, Department of civil engineering, Lehigh University, Bethlehem, Pennsylvania 1967.

[25] Tadros M.K., Morcous G. Impact of Large 0.7 Inch Strand on NU-I Girders. Final Reports Technical Briefs from Mid-America Transportation Centre 2011; 48.

[26] Bailey C. G., Ellobody E. Fire tests on bonded post-tensioned concrete slabs. Engineering Structures 2009; 31: 686-696.

[27] Eurocode1. Actions on structures- Part 1-2: General actions-Actions on structures exposed to fire, British Standards Institution, London 2002. BSEN 1991-1-2.

[28] Zheng W., Hou X. Experiment and analysis on the mechanical behaviour of PC simplysupported slabs subjected to fire. Advances in Structural Engineering 2008; 11(1):71-89. 


\section{Captions of Figures and tables}

Table 1 Values of $C$ and $\mu$ used in proposed model.

Table 2 Three-wire strands parameters.

Table 3 Seven-wire strands parameters.

Table 4 Comparison between the predicted and measured bond stresses for transfer bond tests.

Table 5 Comparison between the predicted and measured bond stresses for flexural bond tests.

Fig. 1 Transfer bond length and flexural bond length before and after loading.

Fig. 2 The interaction between the outer wires of the strand and concrete.

Fig. 3 Parabolic Mohr Envelope [17].

Fig. 4 Bond stress-slip curve a) Three-wire strands, b) Seven-wire strands.

Fig. 5 Bond-link elements.

Fig. 6 Comparison of predicted and tested bond stress-slip curves for the seven-wire smooth strand at ambient temperature [9].

Fig. 7 Comparison of predicted and tested load-slip curves for the flexural bond with seven-wire indented strands at ambient temperature [10].

Fig. 8 Comparison of predicted and tested load-slip curves for the three-wire transfer bond test at ambient temperature [11].

Fig. 9 Comparison of predicted and tested load-slip curves for the three-wire flexural bond test at ambient temperature [11].

Fig. 10 Comparison of predicted and tested bond strength degradation with different concrete compressive strengths at elevated temperatures [23]: (a) $77.4 \mathrm{MPa}$; (b) $98.8 \mathrm{MPa}$.

Fig. 11 Details of tested T-beam Z-1 [24] (all dimensions in mm).

Fig. 12 Comparison of the predicted and tested load versus mid-span deflections curves for T-beam Z-1 [24].

Fig. 13 Details of the tested T-girder (T-6-1.5h-A) [25] (all dimensions in mm).

Fig. 14 Comparison of the predicted and tested load versus mid-span deflections curves for the tested T-girder [25].

Fig. 15 Details of PC Slab TB3 [26] (all dimensions in mm).

Fig. 16 Comparison between the predicted and tested temperature histories [26].

Fig. 17 Comparison of predicted and measured mid-span deflections of Slab TB3 [26].

Fig. 18 Comparison of predicted and tested longitudinal expansion for Slab TB3 [26].

Fig. 19 Details of PC Slab PSS-1 [28].

Fig. 20 Heating curve used in the analysis [28].

Fig. 21 The predicted and tested temperature histories for Slab PSS-1 [28].

Fig. 22 Comparison of predicted and measured mid-span deflections of Slab PSS-1 [28]. 


\section{Tables and Figures}

Table 1. Values of $C$ and $\mu$ used in proposed model.

\begin{tabular}{|c|c|c|c|c|}
\hline \multirow{2}{*}{ Type of strand } & \multicolumn{2}{|c|}{ Smooth } & \multicolumn{2}{c|}{ Indented } \\
\cline { 2 - 5 } & $C$ & $\mu$ & $C$ & $\mu$ \\
\hline Three-wire strands & 1.3 & 0.4 & 1.7 & 0.6 \\
\hline Seven-wire strands & 1.3 & 0.4 & 1.6 & 0.5 \\
\hline
\end{tabular}

Table 2 Three-wire strands parameters.

\begin{tabular}{|c|c|c|}
\hline Type of strand & Smooth & Indented \\
\hline$S_{1}$ & 0.5 & 1.0 \\
\hline$S_{2}$ & 0.5 & 3.5 \\
\hline$S_{3}$ & 5.0 & 5.0 \\
\hline$\tau$ & $\tau_{3}=0.35 \tau_{\max }$ & $\tau_{3}=0.65 \tau_{\max }$ \\
\hline
\end{tabular}

Table 3 Seven-wire strands parameters.

\begin{tabular}{|c|c|c|}
\hline Type of strand & Smooth & Indented \\
\hline$S_{1}$ & 0.25 & 1.0 \\
\hline$S_{2}$ & 0.5 & 3.5 \\
\hline$S_{3}$ & 3.5 & 6.0 \\
\hline$S_{4}$ & 8.0 & - \\
\hline$\tau$ & $\tau_{2}=0.75 \tau_{\max }$ & $\tau_{3}=0.35 \tau_{\max }$ \\
\hline & $\tau_{4}=0.35 \tau_{\max }$ & \\
\hline
\end{tabular}

Table 4 Comparison between the predicted and measured bond stresses for transfer bond tests.

\begin{tabular}{|c|c|c|c|c|c|c|}
\hline Specimen & $d_{s} \mathrm{~mm}$ & $P_{1} \mathrm{kN}$ & $P_{2} \mathrm{kN}$ & $\begin{array}{c}\Delta P=P_{1}-P_{2} \\
\mathrm{kN}\end{array}$ & $\begin{array}{c}\text { Bond strength } \\
\mathrm{MPa} \text { (test) }\end{array}$ & $\begin{array}{c}\text { Bond strength } \\
\text { MPa (predicted) }\end{array}$ \\
\hline $9.5-\mathrm{A}-2$ & 9.5 & 69 & 6 & 63.0 & 6.7 & 6.1 \\
\hline $13-\mathrm{A}-2$ & 13 & 123 & 32 & 92.0 & 6.9 & 6.2 \\
\hline $16-\mathrm{A}-2$ & 16 & 160 & 41 & 119.0 & 7.1 & 6.35 \\
\hline
\end{tabular}

Table 5 Comparison between the predicted and measured bond stresses for flexural bond tests.

\begin{tabular}{|c|c|c|c|}
\hline specimen & $d_{s} \mathrm{~mm}$ & $\begin{array}{c}\text { Bond strength } \\
\text { MPa (test) }\end{array}$ & $\begin{array}{c}\text { Bond strength } \\
\text { MPa (predicted) }\end{array}$ \\
\hline $9.5-\mathrm{B}-1$ & 9.5 & 4.2 & 3.8 \\
\hline $13-\mathrm{B}-1$ & 13 & 3.6 & 3.6 \\
\hline $16-\mathrm{B}-2$ & 16 & 3.7 & 3.65 \\
\hline
\end{tabular}




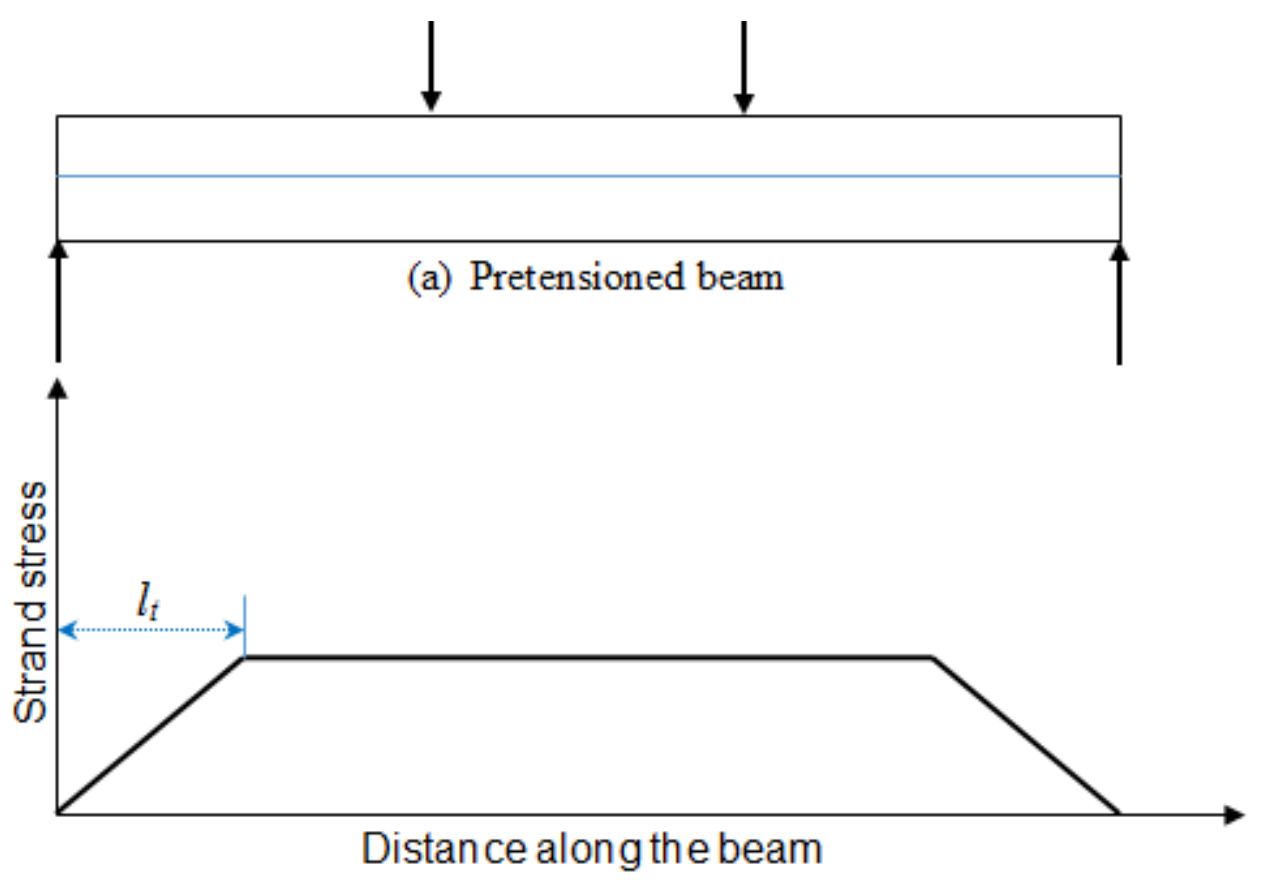

(b) Variation of stress in the strand after release the stress before loading

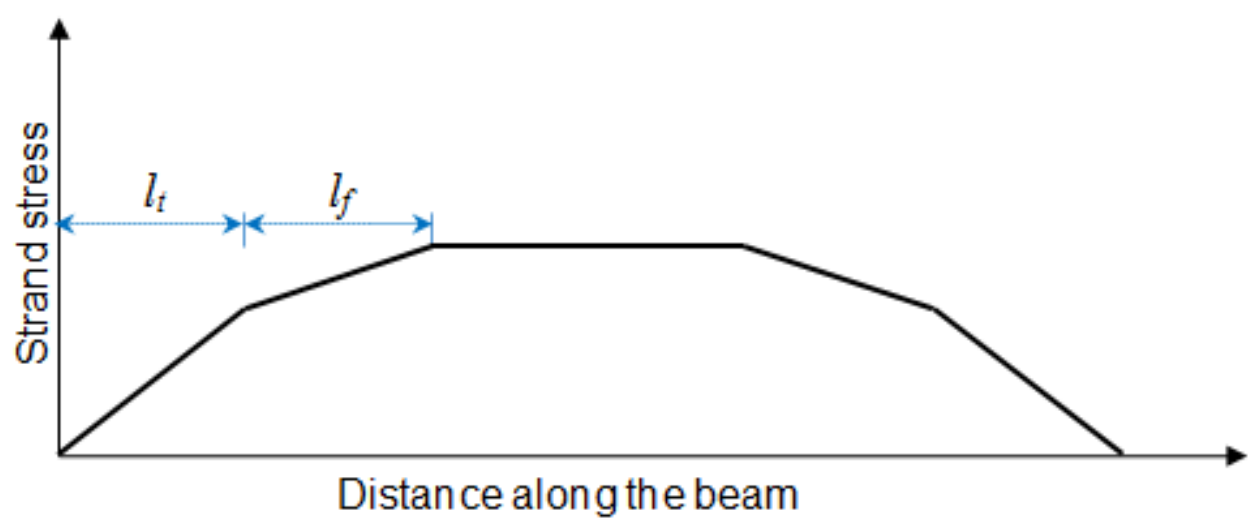

(c) Variation of stress in the strand after loading

Fig. 1 Transfer bond length and flexural bond length before and after loading.

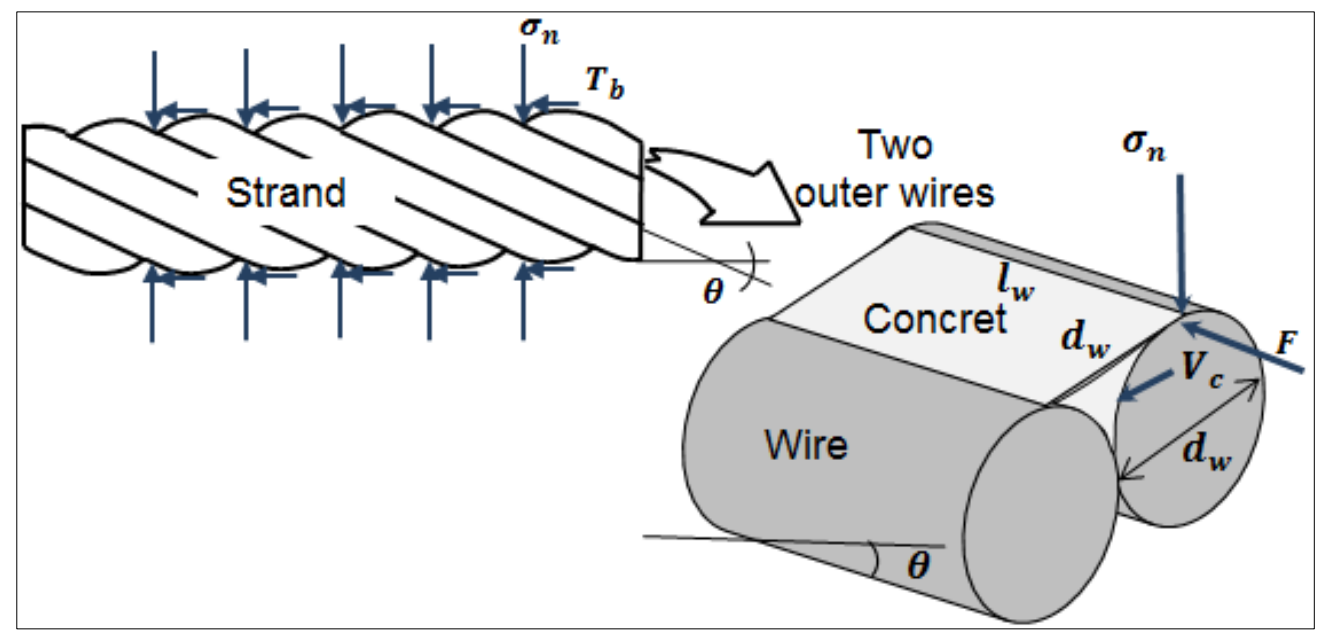

Fig. 2 The interaction between the outer wires of the strand and concrete. 


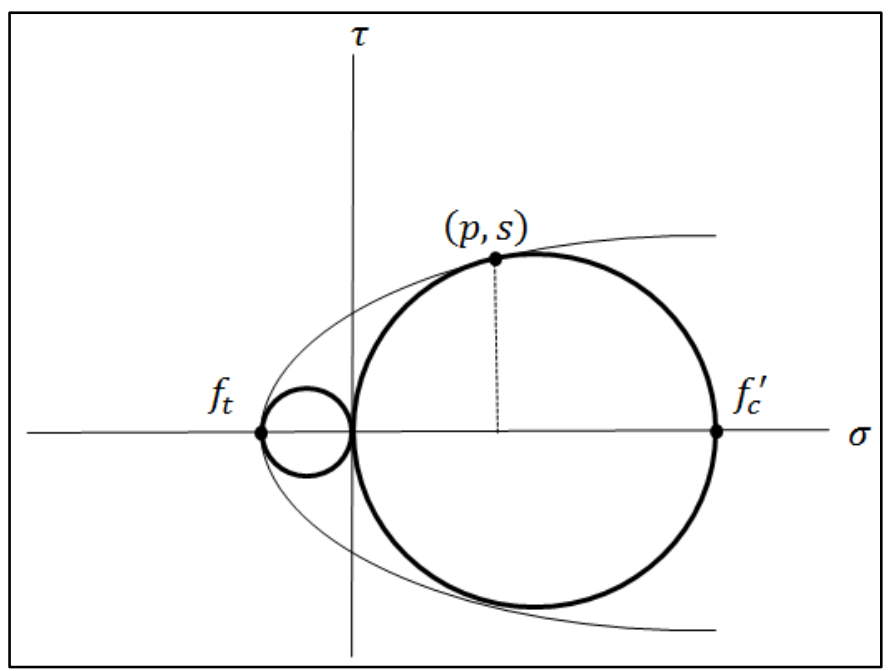

Fig. 3 Parabolic Mohr Envelope [14].
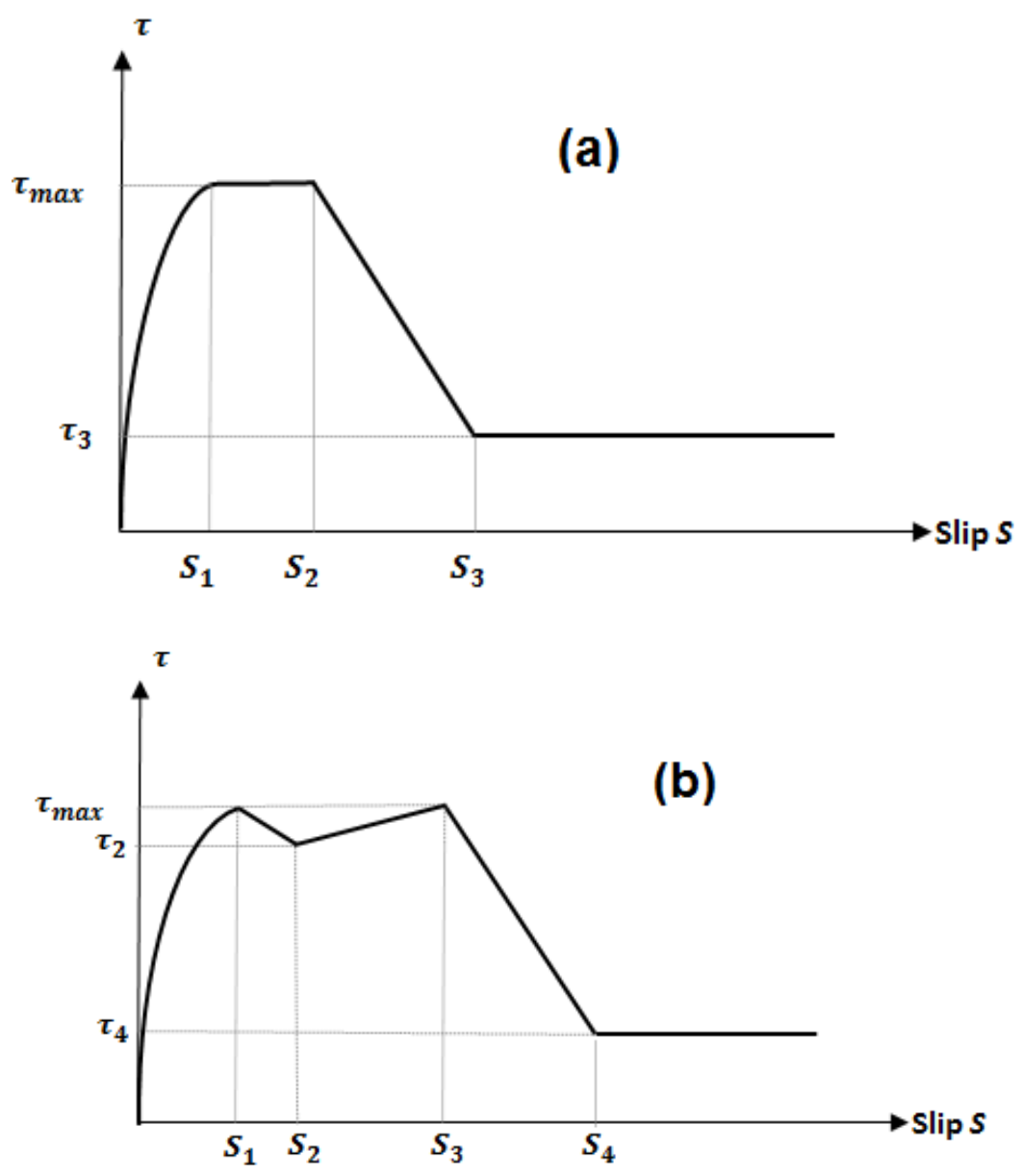

Fig. 4 Bond stress-slip curve: (a) Three-wire strands, (b) Seven-wire strands. 


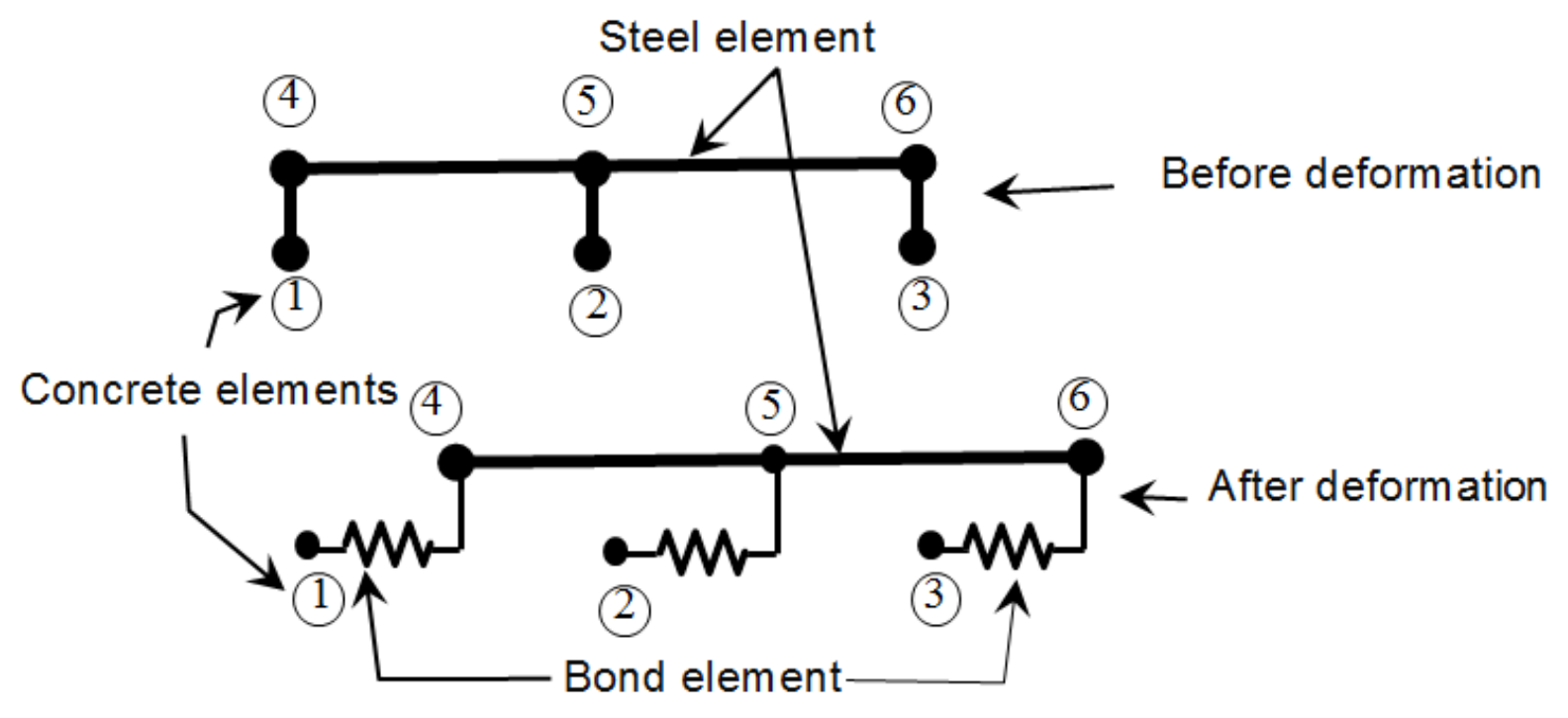

Fig. 5 Bond-link elements.

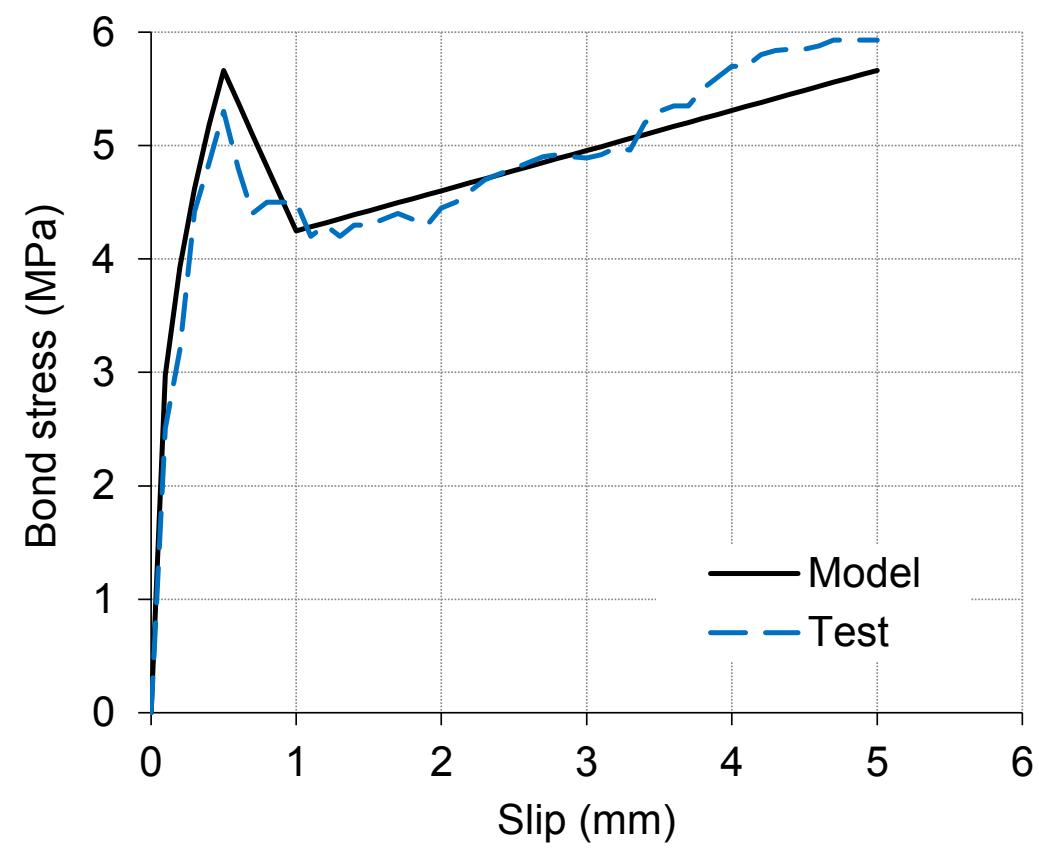

Fig. 6 Comparison of predicted and tested bond stress-slip curves for the seven-wire smooth strand at ambient temperature [9]. 


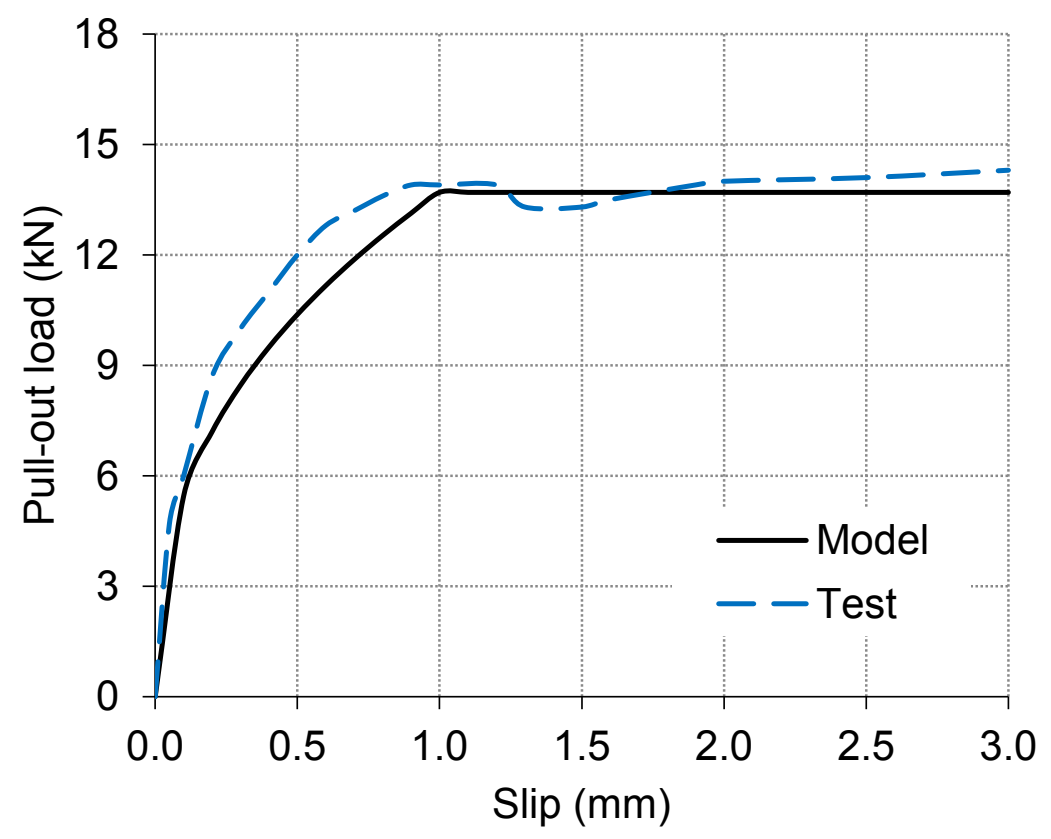

Fig. 7 Comparison of predicted and tested load-slip curves for the flexural bond with seven-wire indented strands at ambient temperature [10].

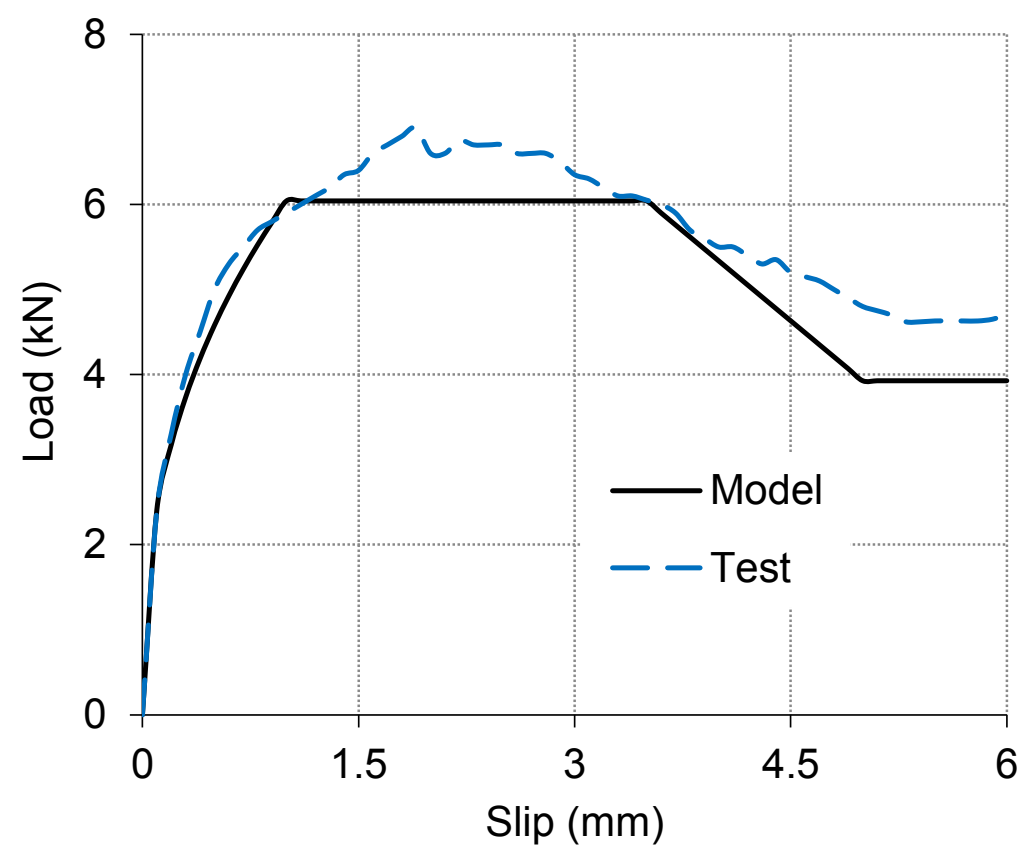

Fig. 8 Comparison of predicted and tested load-slip curves for the three-wire transfer bond test at ambient temperature [11]. 


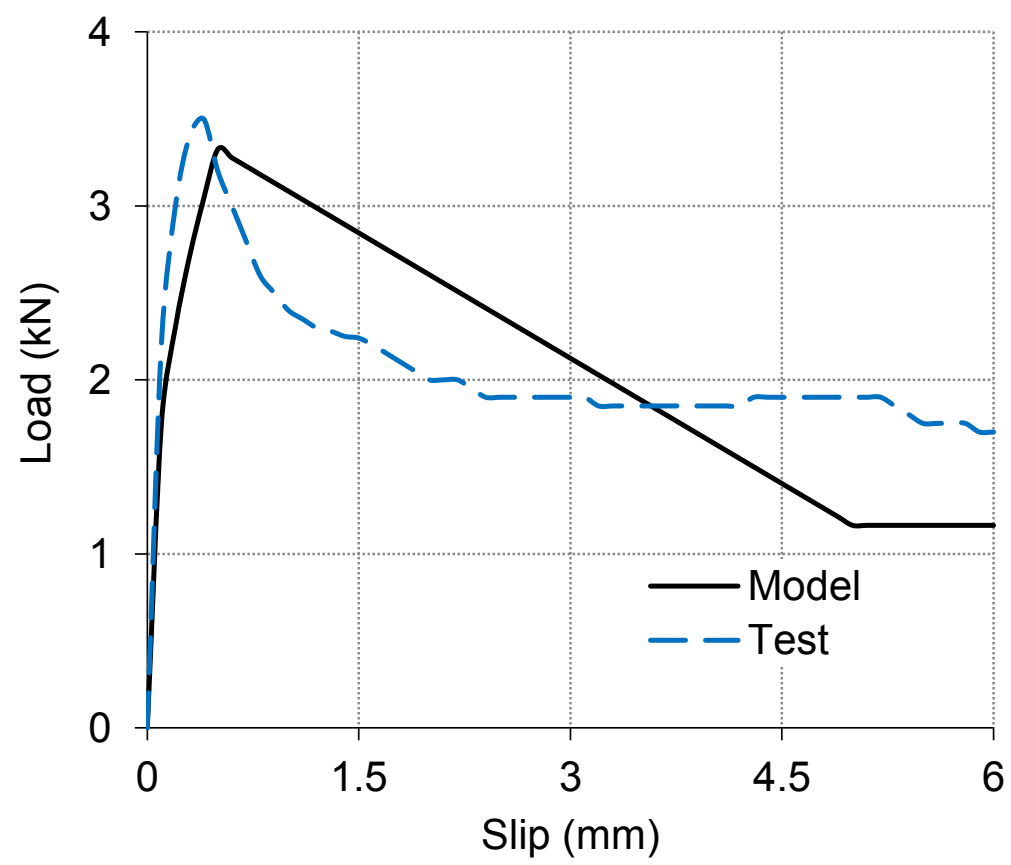

Fig. 9 Comparison of predicted and tested load-slip curves for the three-wire flexural bond test at ambient temperature [11].

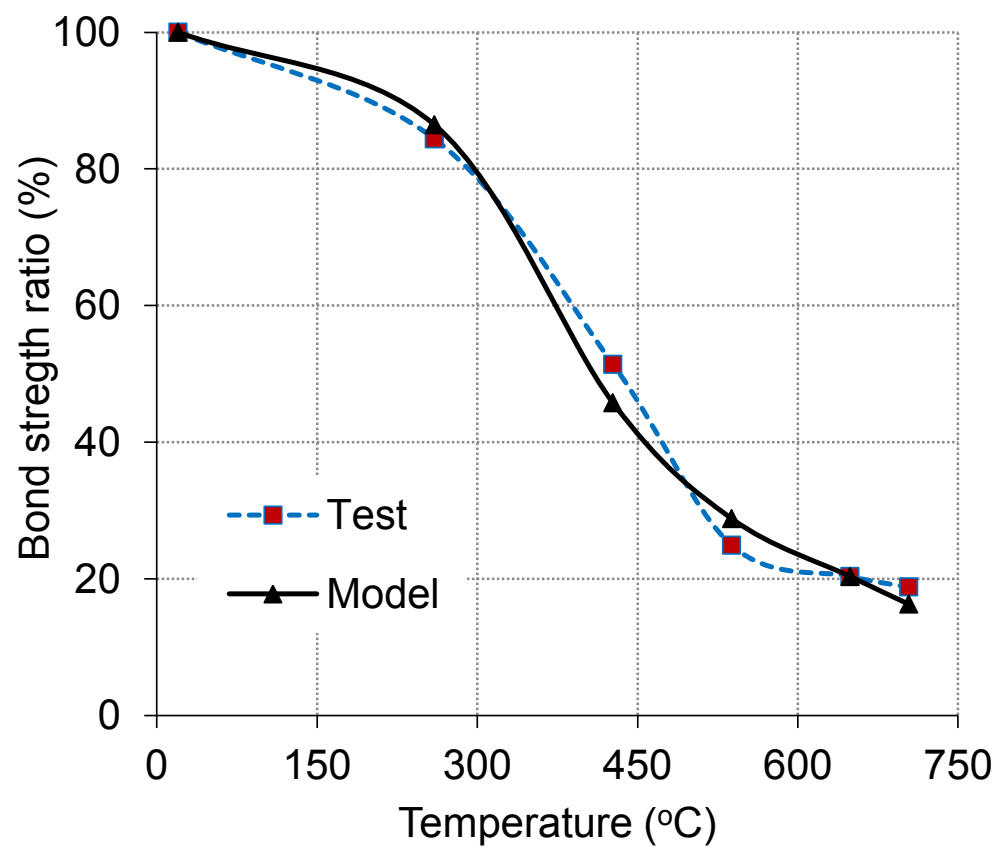

(a) 


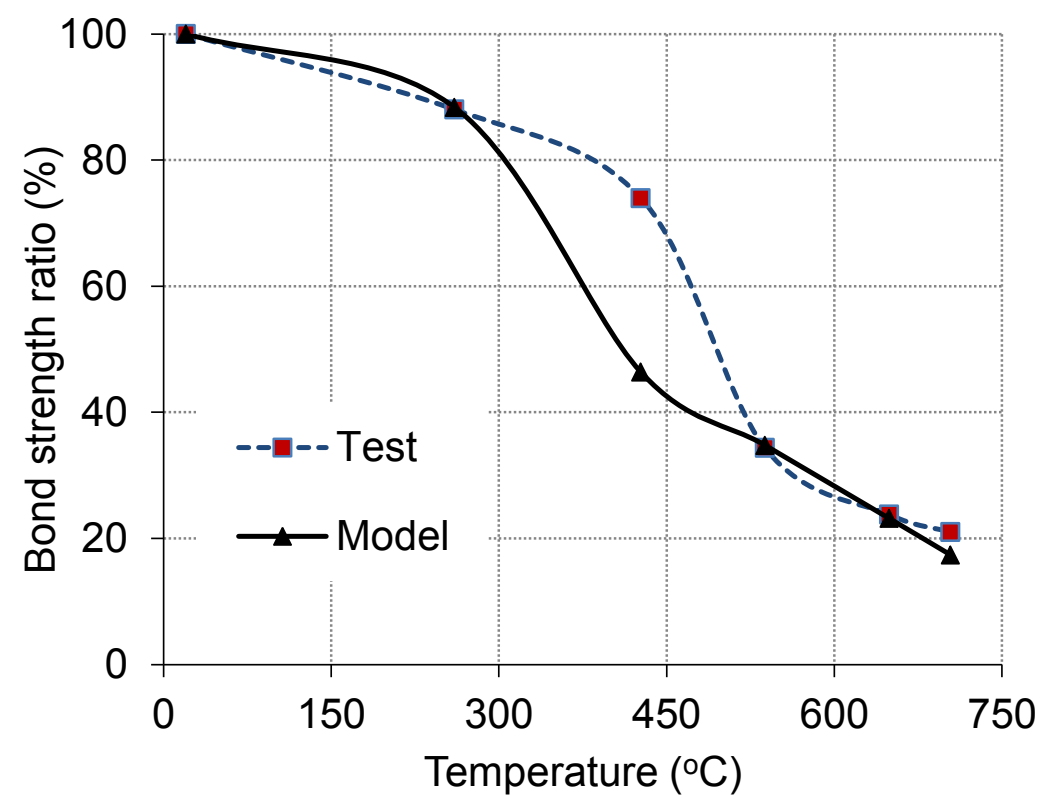

(b)

Fig. 10 Comparison of predicted and tested bond strength degradation with different concrete compressive strengths at elevated temperatures [23]: (a) $77.4 \mathrm{MPa}$; (b) $98.8 \mathrm{MPa}$.

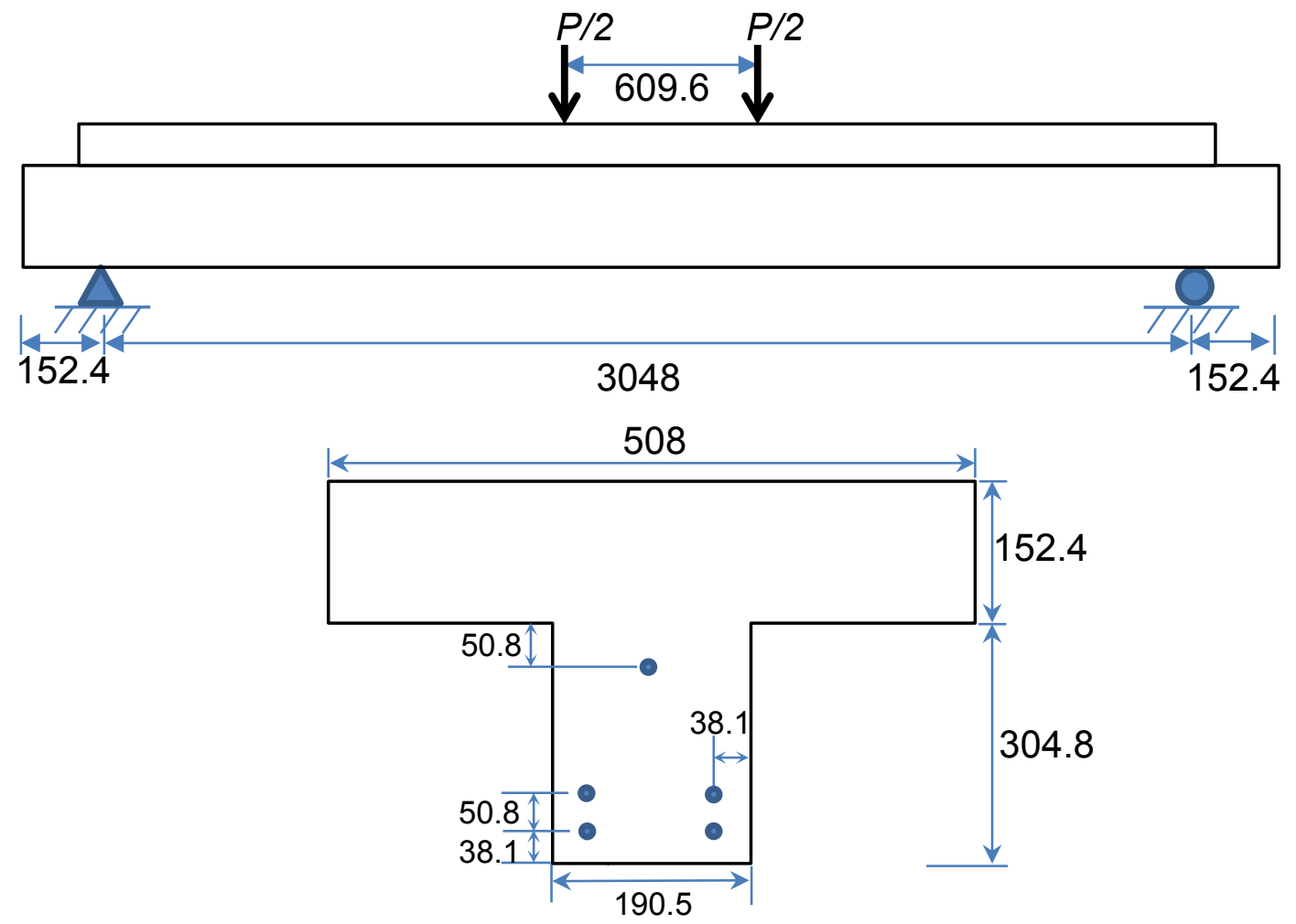

Fig. 11 Details of tested T-beam Z-1 [24] (all dimensions in mm). 


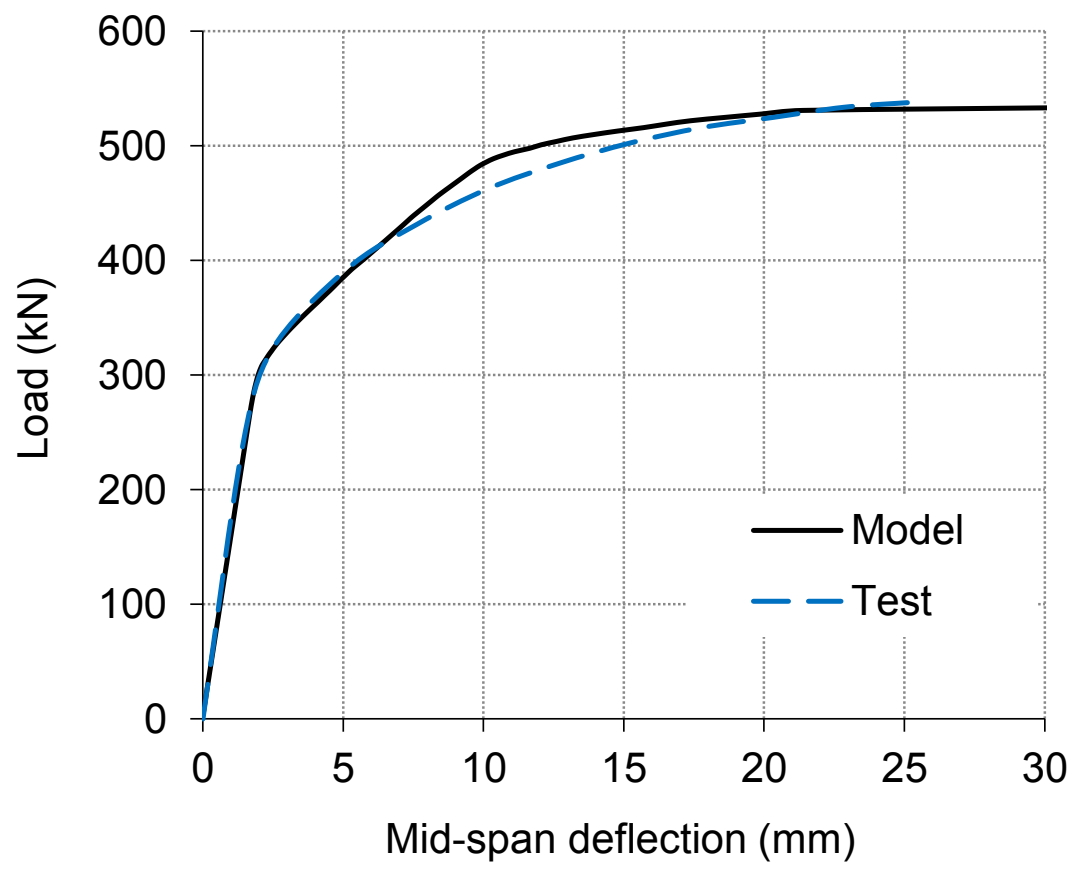

Fig. 12 Comparison of the predicted and tested load versus mid-span deflections curves for Tbeam Z-1 [24].

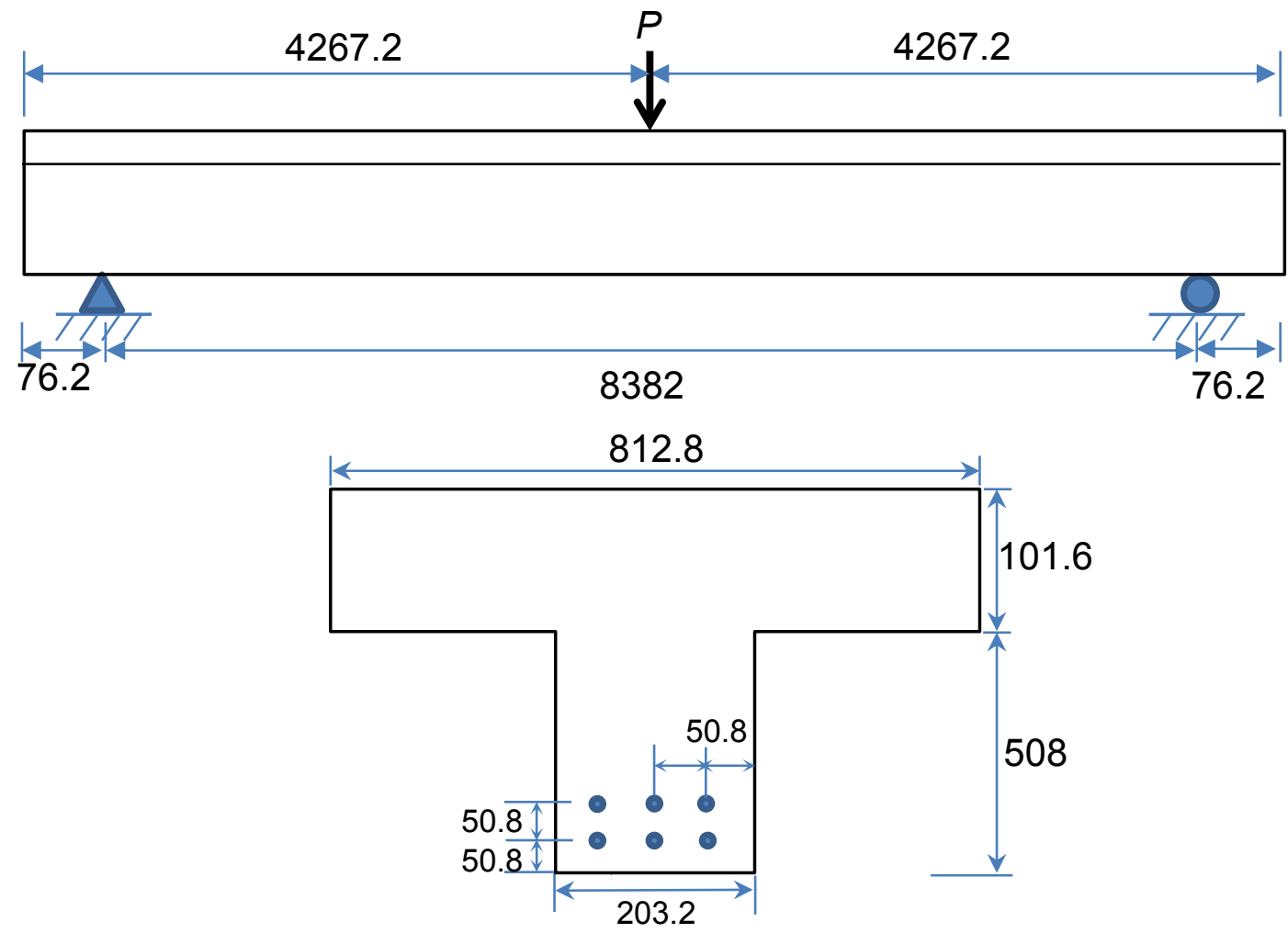

Fig. 13 Details of the tested T-girder (T-6-1.5h-A) [25] (all dimensions in mm). 


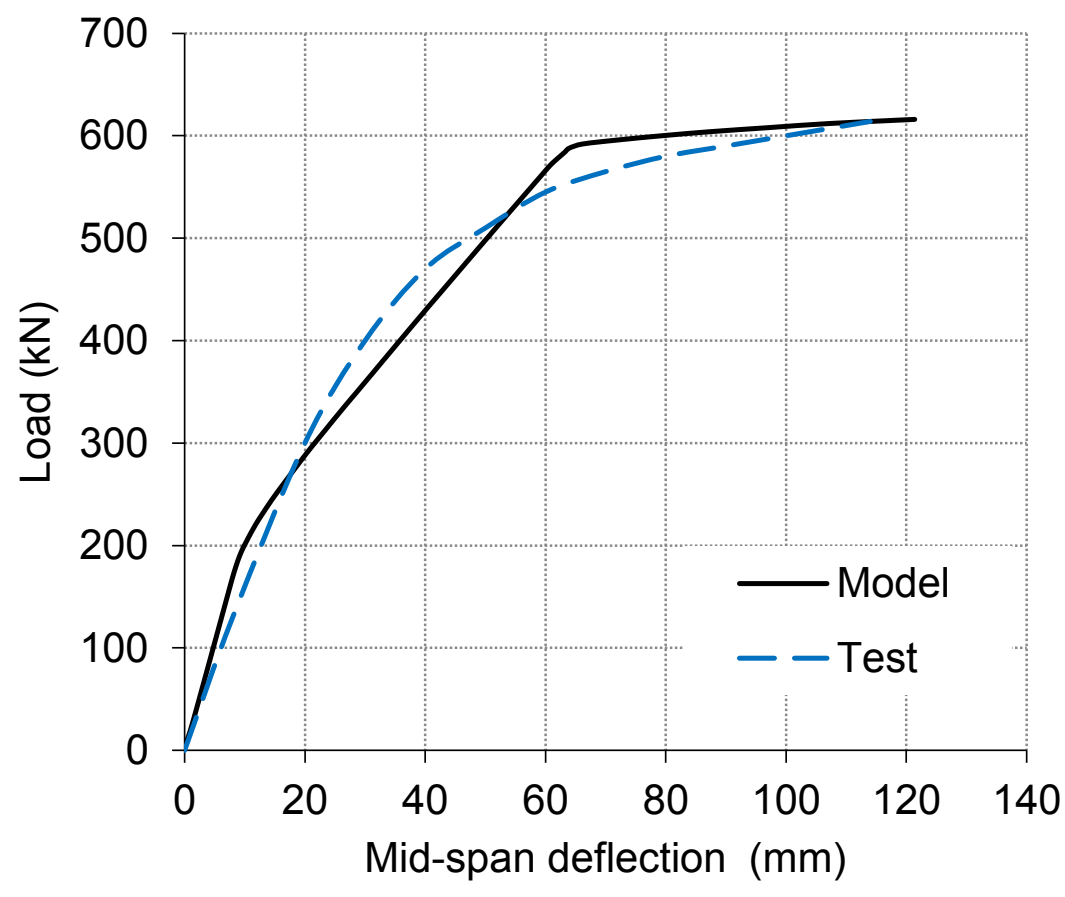

Fig. 14 Comparison of the predicted and tested load versus mid-span deflections curves for the tested T-girder [25].
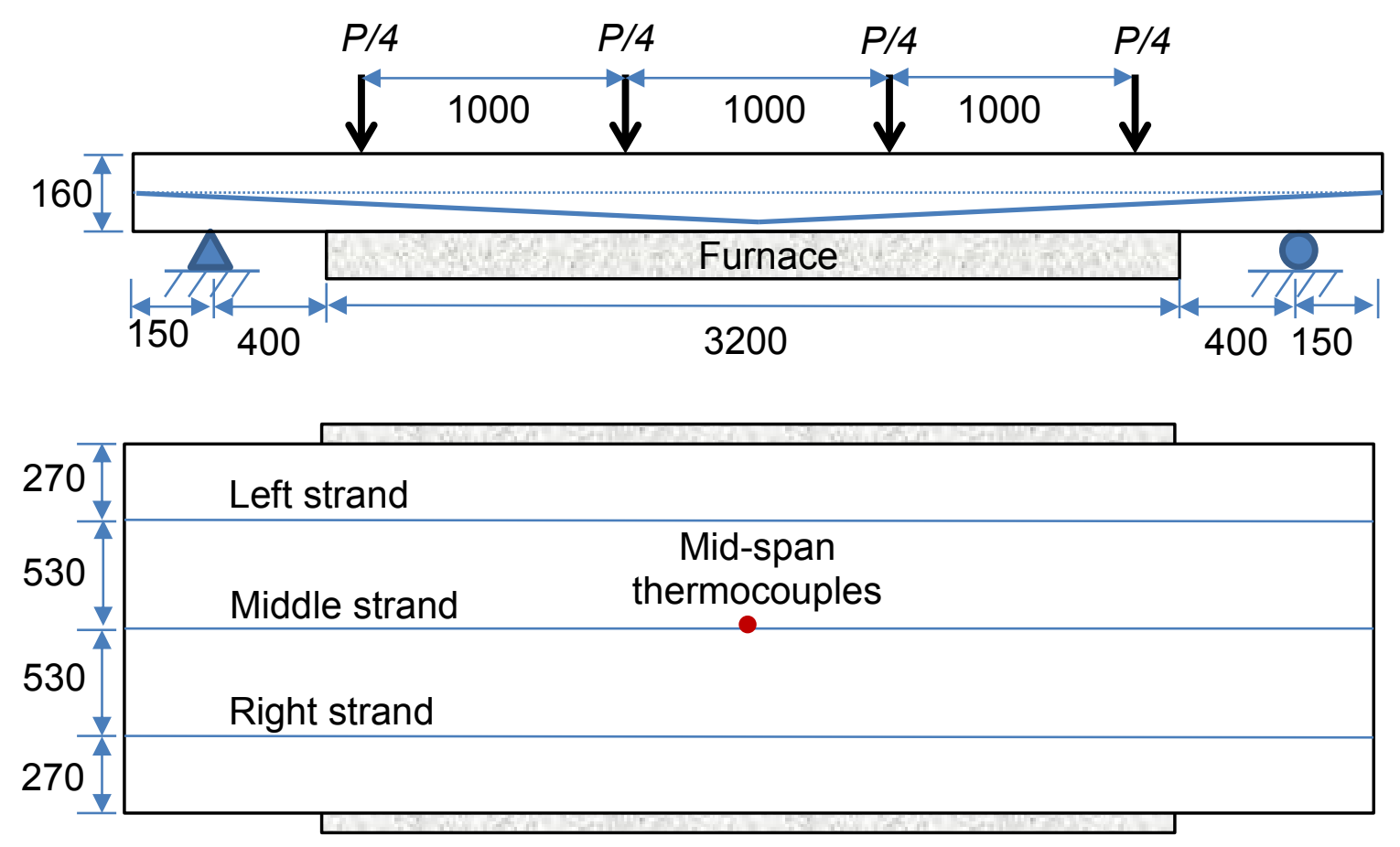

Fig. 15 Details of PC Slab TB3 [26] (all dimensions in mm). 


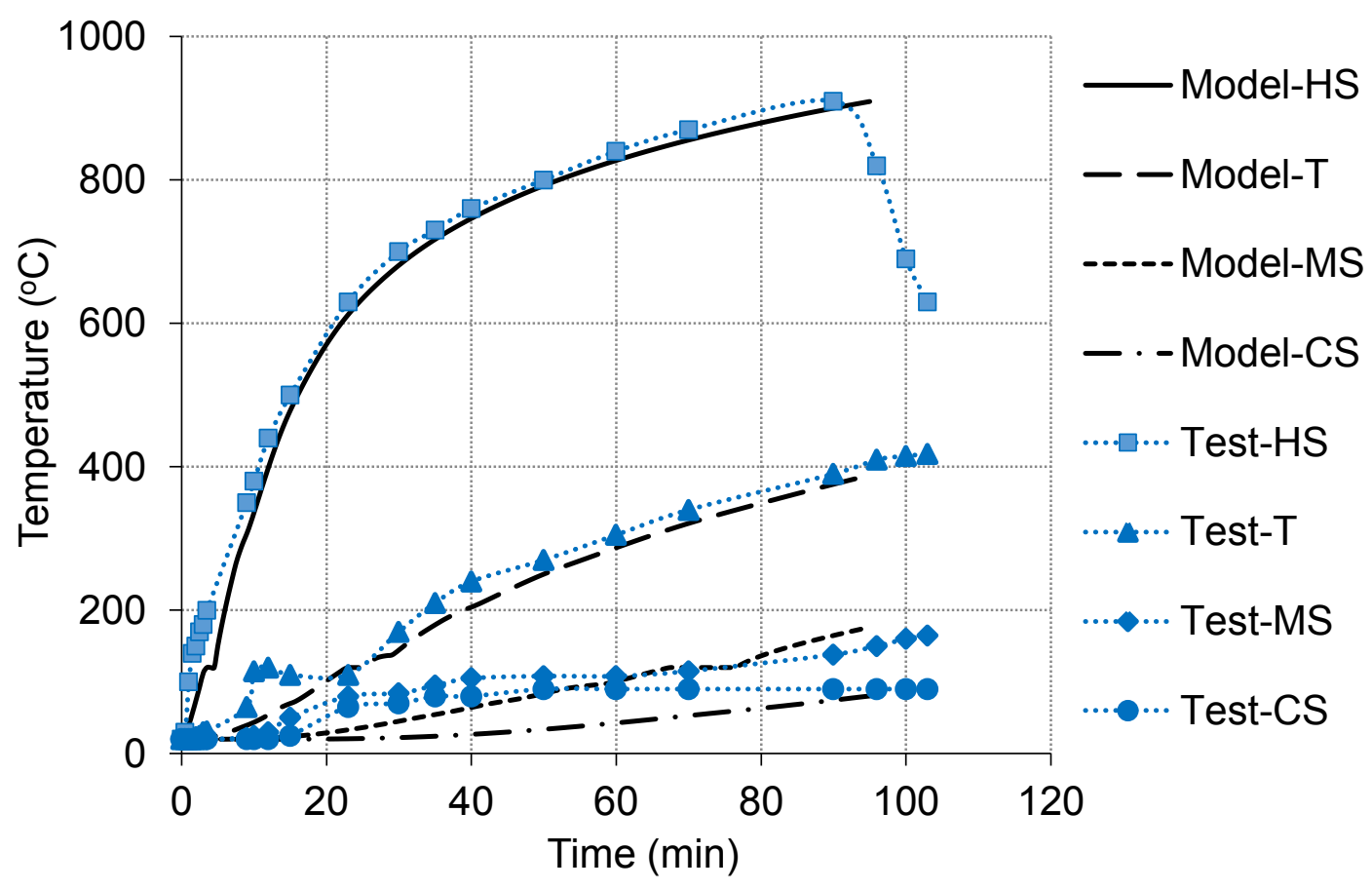

Fig. 16 Comparison between the predicted and tested temperature histories [26].

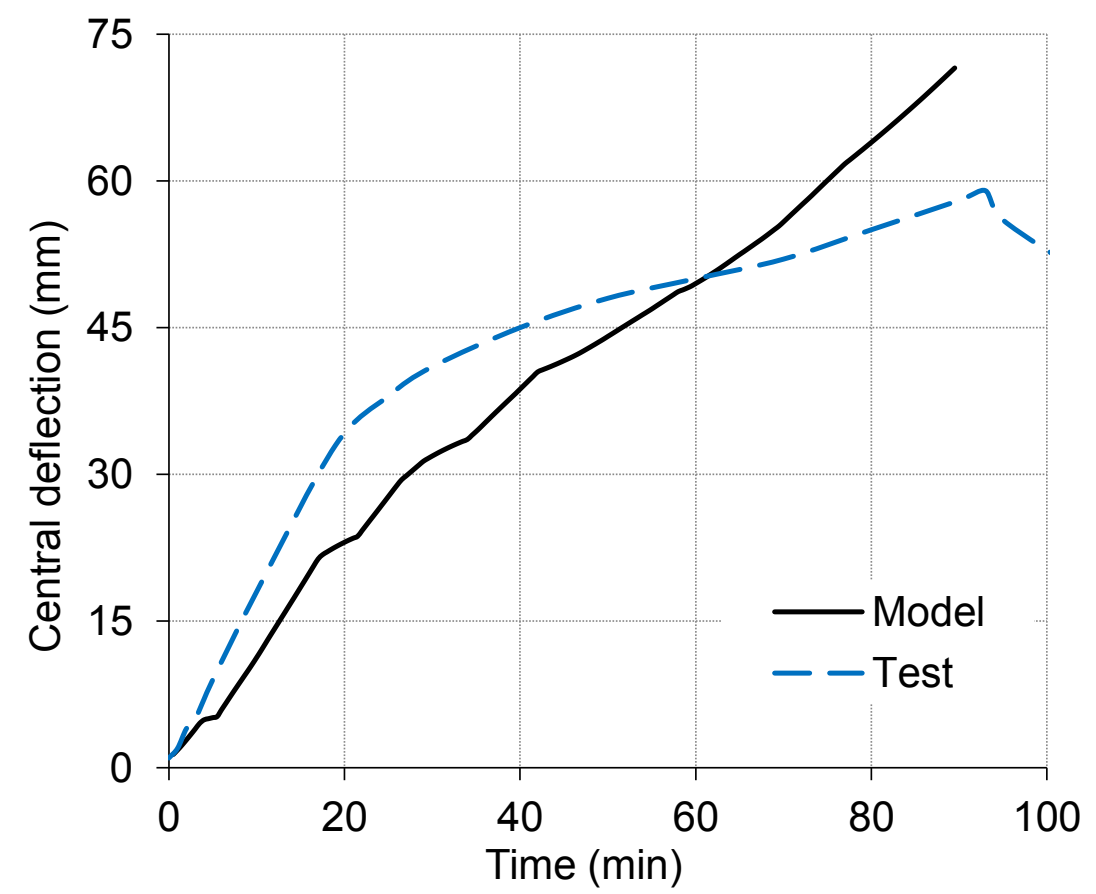

Fig. 17 Comparison of predicted and measured mid-span deflections of Slab TB3 [26]. 


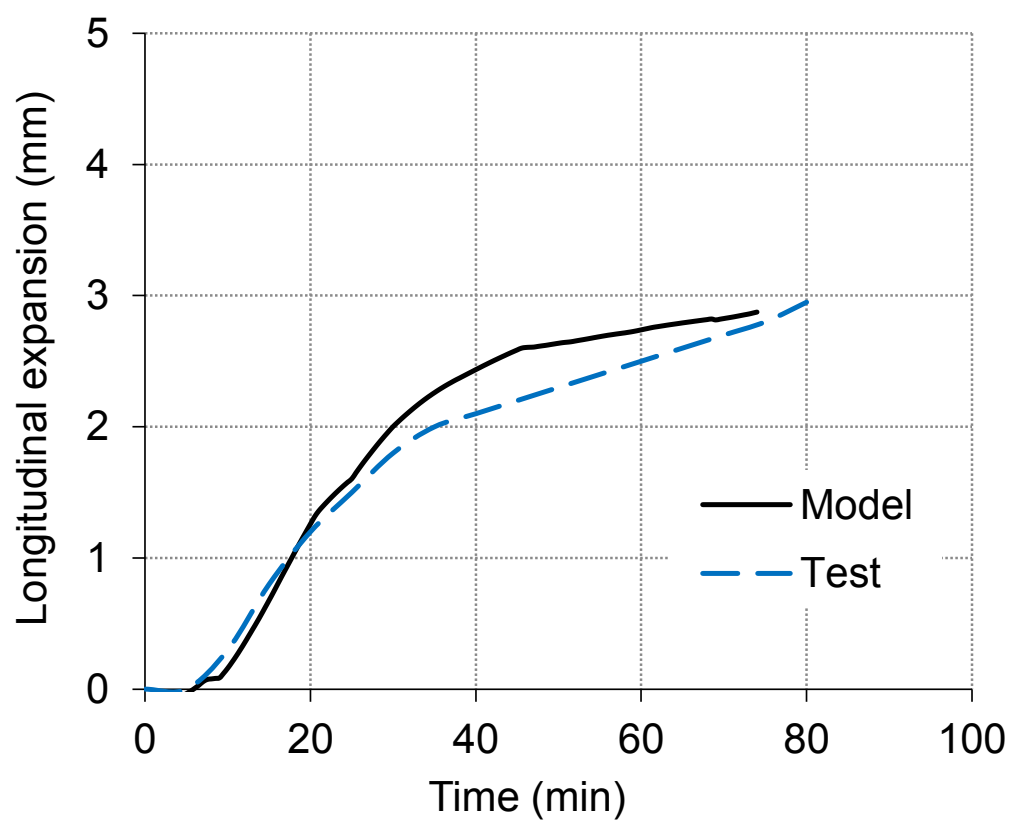

Fig. 18 Comparison of predicted and tested longitudinal expansion for Slab TB3 [26].

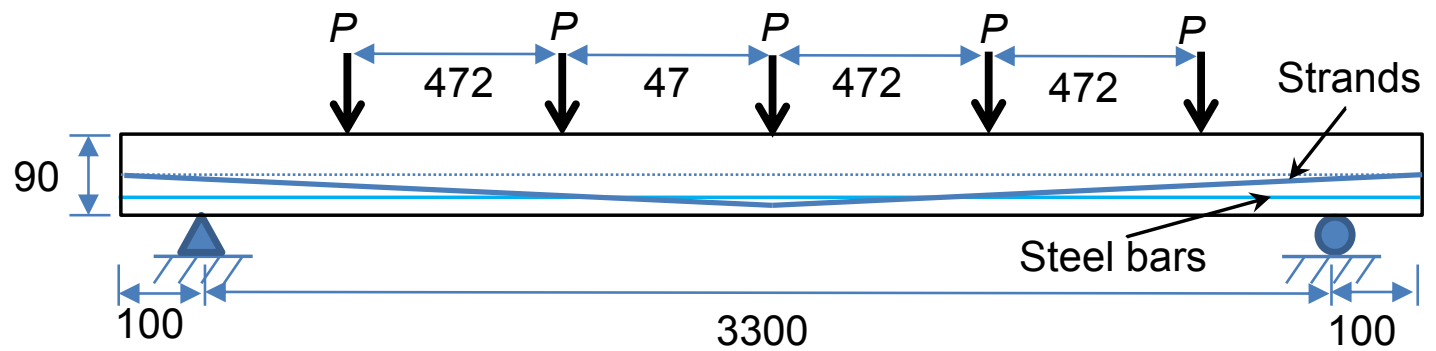

Steel bars

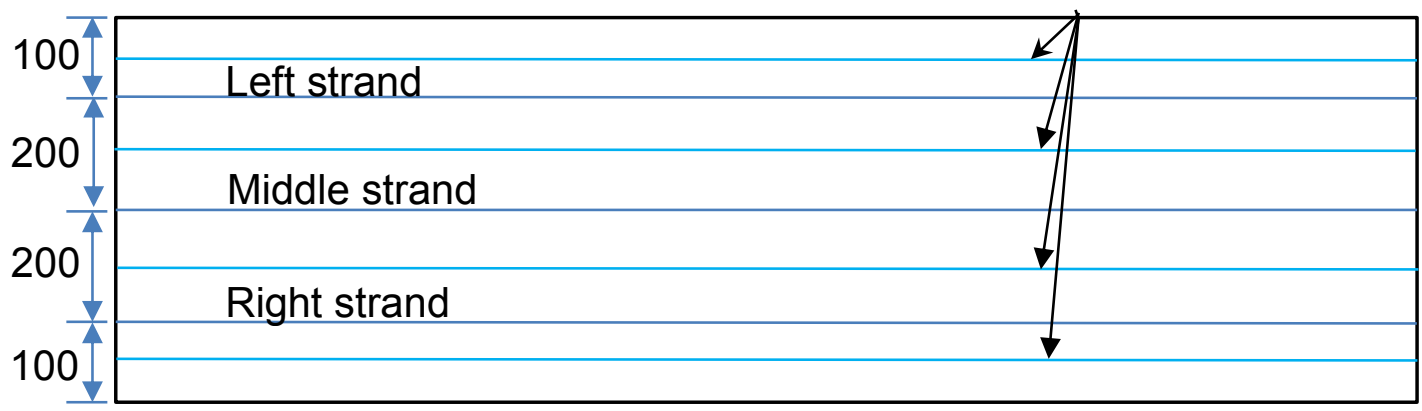

Fig. 19 Details of PC Slab PSS-1 [28]. 


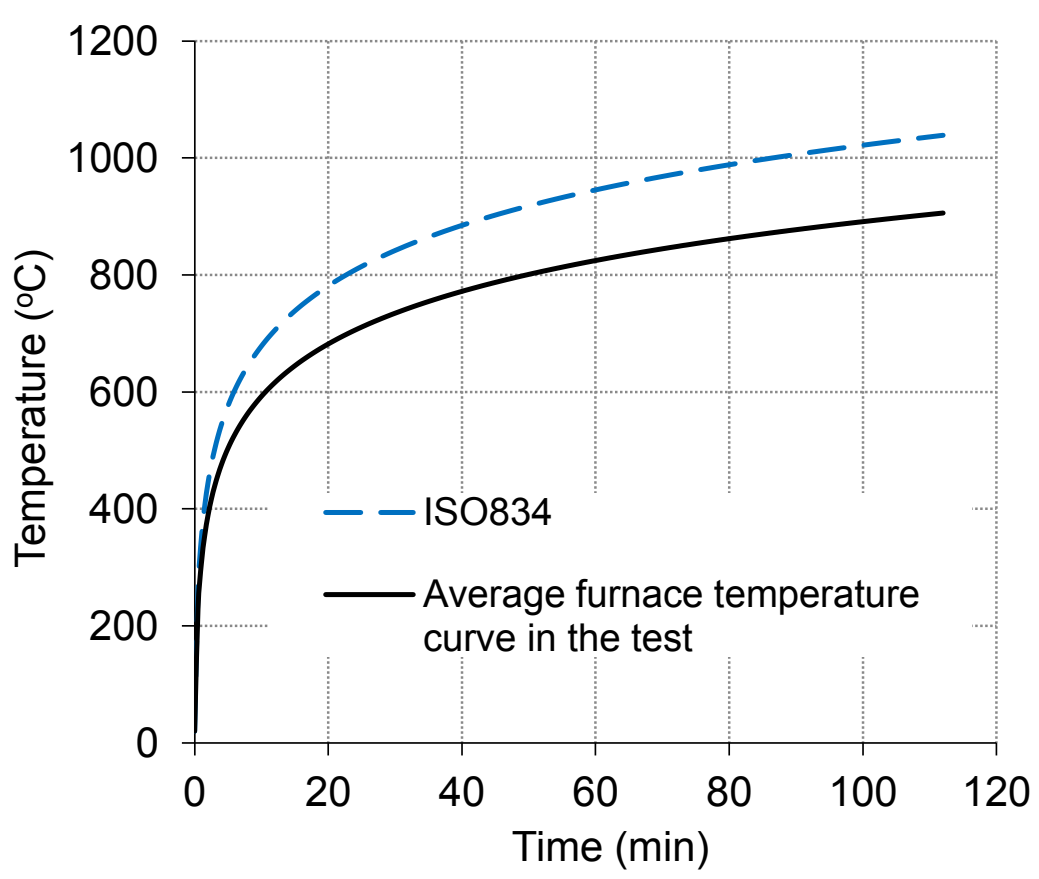

Fig. 20 Heating curve used in the analysis [28].

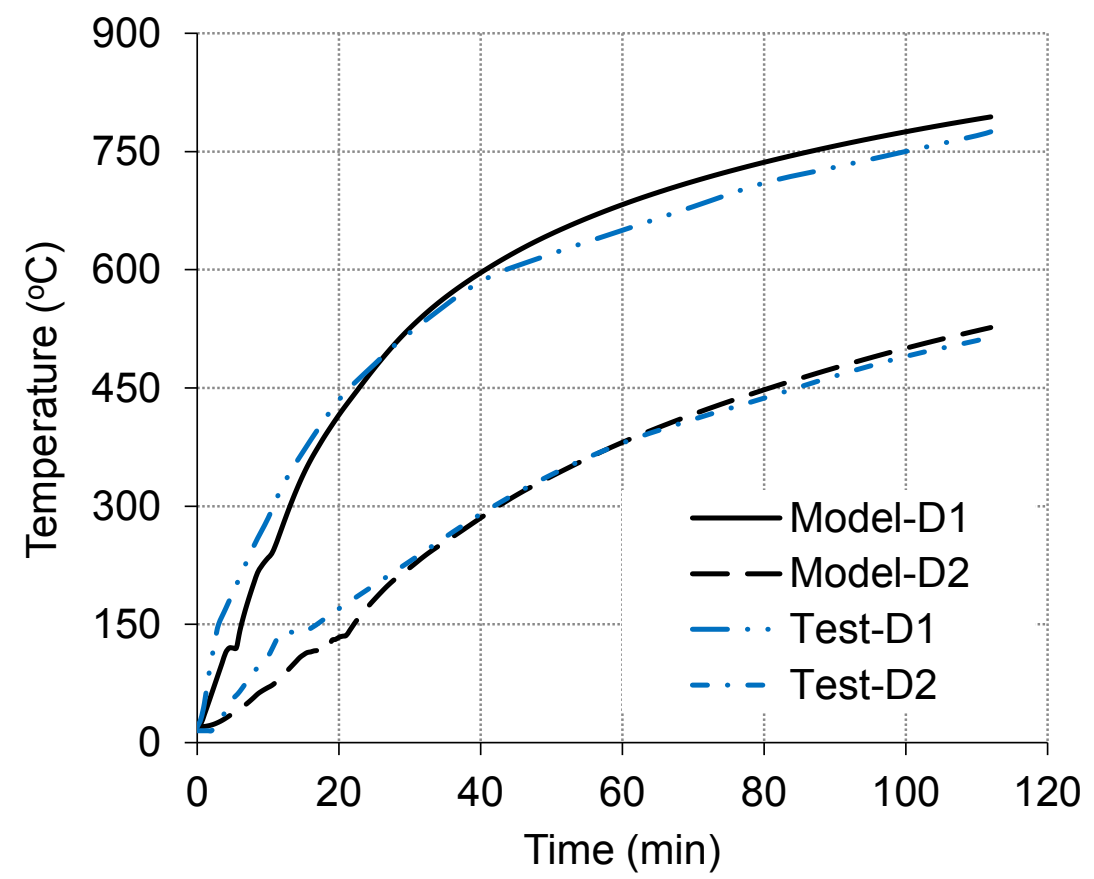

Fig. 21 The predicted and tested temperature histories for Slab PSS-1 [28]. 


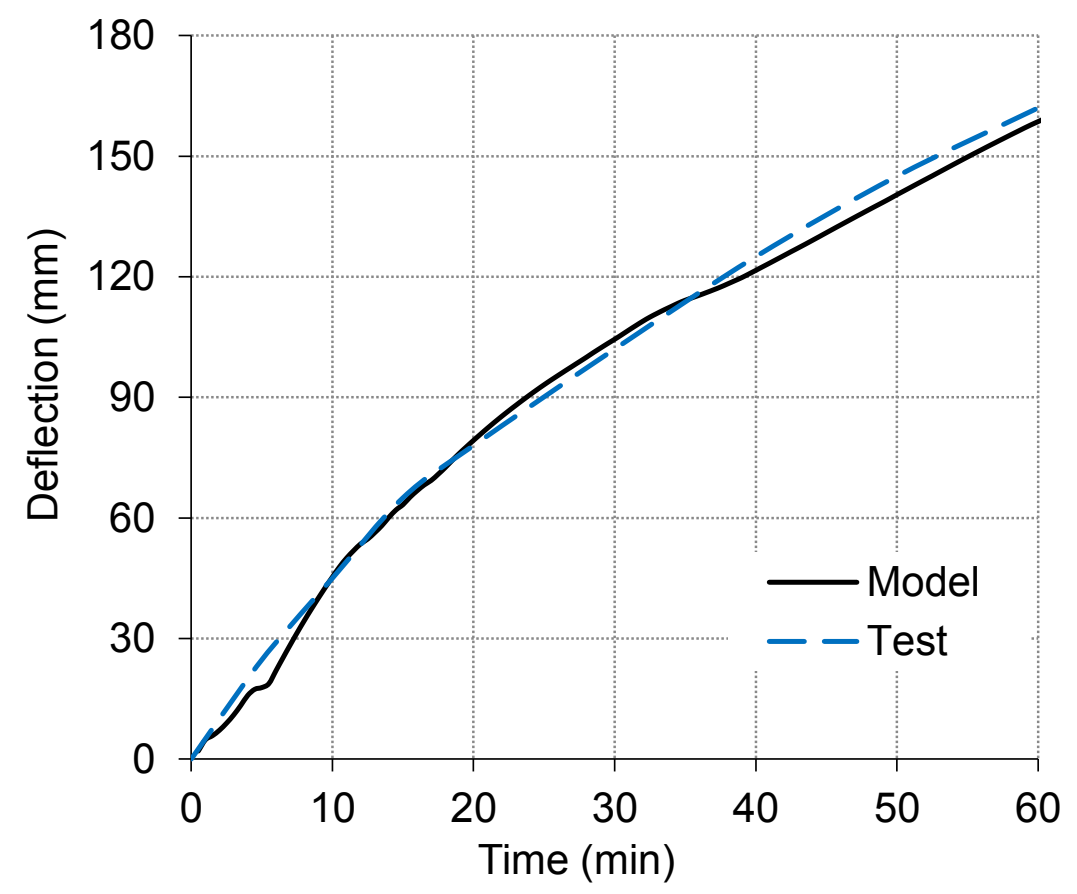

Fig. 22 Comparison of predicted and measured mid-span deflections of Slab PSS-1 [28]. 